\title{
CAMA
}

Centre for Applied Macroeconomic Analysis

\section{Insurance in Human Capital Models with Limited Enforcement}

\section{CAMA Working Paper 48/2016 August 2016}

\section{Tom Krebs}

University of Mannheim

IZA

\section{Moritz Kuhn}

University of Bonn

IZA

\author{
Mark Wright \\ FRB Chicago \\ NBER \\ Centre for Applied Macroeconomic Analysis, ANU
}

\section{Abstract}

This paper develops a tractable human capital model with limited enforceability of contracts. The model economy is populated by a large number of long-lived, risk-averse households with homothetic preferences who can invest in risk-free physical capital and risky human capital. Households have access to a complete set of credit and insurance contracts, but their ability to use the available financial instruments is limited by the possibility of default (limited contract enforcement). We provide a convenient equilibrium characterization that facilitates the computation of recursive equilibria substantially. We use a calibrated version of the model with stochastically aging households divided into 9 age groups. Younger households have higher expected human capital returns than older households. According to the baseline calibration, for young households less than half of human capital risk is insured and the welfare losses due to the lack of insurance range from 3 percent of lifetime consumption (age 40) to 7 percent of lifetime consumption (age 23). Realistic variations in the model parameters have non-negligible effects on equilibrium insurance and welfare, but the result that young households are severely underinsured is robust to such variations. 


\section{Keywords}

Human Capital Risk, Limited Enforcement, Insurance

JEL Classification

E21, E24, D52, J24

Address for correspondence:

(E) cama.admin@anu.edu.au

ISSN 2206-0332

The Centre for Applied Macroeconomic Analysis in the Crawford School of Public Policy has been established to build strong links between professional macroeconomists. It provides a forum for quality macroeconomic research and discussion of policy issues between academia, government and the private sector.

The Crawford School of Public Policy is the Australian National University's public policy school, serving and influencing Australia, Asia and the Pacific through advanced policy research, graduate and executive education, and policy impact. 


\title{
Insurance in Human Capital Models with Limited Enforcement
}

\author{
Tom Krebs \\ University of Mannheim and IZA \\ Moritz Kuhn \\ University of Bonn and IZA \\ Mark Wright \\ FRB Chicago, CAMA and NBER
}

April 2016

\begin{abstract}
This paper develops a tractable human capital model with limited enforceability of contracts. The model economy is populated by a large number of long-lived, risk-averse households with homothetic preferences who can invest in risk-free physical capital and risky human capital. Households have access to a complete set of credit and insurance contracts, but their ability to use the available financial instruments is limited by the possibility of default (limited contract enforcement). We provide a convenient equilibrium characterization that facilitates the computation of recursive equilibria substantially. We use a calibrated version of the model with stochastically aging households divided into 9 age groups. Younger households have higher expected human capital returns than older households. According to the baseline calibration, for young households less than half of human capital risk is insured and the welfare losses due to the lack of insurance range from 3 percent of lifetime consumption (age 40) to 7 percent of lifetime consumption (age 23). Realistic variations in the model parameters have non-negligible effects on equilibrium insurance and welfare, but the result that young households are severely underinsured is robust to such variations.
\end{abstract}

Keywords: Human Capital Risk, Limited Enforcement, Insurance

JEL Codes: E21, E24, D52, J24

${ }^{*}$ We thank our discussant, Andrew Glover, and seminar participants at various institutions and conferences for useful comments. Tom Krebs thanks the German Research Foundation for support under grant KR3564/2-1. The views expressed herein are those of the authors and not necessarily those of the Federal Reserve Bank of Chicago or the Federal Reserve System. 


\section{Introduction}

Many households own almost nothing but their human capital. Moreover, there is strong evidence that human capital investment is risky, while consumption insurance against this risk is far from complete. In other words, a significant fraction of labor income is the return to human capital investment, and a voluminous empirical literature has shown that individual households face large and highly persistent labor income shocks that have strong effects on individual consumption. In this paper, we argue that one financial friction-limited contract enforcement - can explain a substantial part of the observed lack of consumption insurance. Intuitively, in equilibrium households with high human capital returns and little financial wealth would like to borrow in order to buy insurance and invest in human capital, but they cannot do so because of borrowing constraints that arise endogenously due to the limited enforceability of credit contracts.

Our analysis proceeds in two steps. First, we develop a tractable human capital model with limited contract enforcement and provide a useful equilibrium characterization result. Second, we show that a calibrated macro model with physical capital, human capital, and limited contract enforcement can explain the observed lack of consumption insurance for a large group of households. Moreover, we show that this result is robust to realistic variations in the model parameters describing human capital risk, risk aversion, and contract enforcement.

The model developed in this paper is a version of the type of human capital model that has been popular in the endogenous growth literature. More specifically, we consider a production economy with an aggregate constant-returns-to-scale production function using physical and human capital as input factors. There are a large number (a continuum) of individual households with CRRA-preferences who can invest in risk-free physical capital and risky human capital. Human capital investment is risky due to shocks to the stock 
of human capital that follow a stationary Markov process with finite support (a Markov chain). In the main part of the paper, we assume that all shocks are idiosyncratic, but we also discuss how our theoretical characterization result can be extended to the case in which idiosyncratic and aggregate shocks co-exists. Households have access to a complete set of credit and insurance contracts, but their ability to use the available financial instruments is limited by the possibility of default, which produces endogenous borrowing, or short-sale, constraints. Defaulting households continue to participate in the labor market, but part of their labor income might be garnished and they are excluded from financial markets until a stochastically determined future date.

The tractability of the model derives from two equilibrium characterization results. First, the consumption-investment choice of households is linear in total wealth (financial wealth plus human capital) and the portfolio choice of households is independent of wealth. Further, the solution to the household decision problem can be obtained solving a static maximization problem. Moreover, the maximization problem of individual households is shown to be convex so that a simple FOC-approach is applicable. Second, recursive equilibria can be found by solving a fixed-point problem that is independent of the wealth distribution. Thus, a rather complex, infinite-dimensional fixed-point problem has been transformed into a much simpler, finite-dimensional fixed-point problem.

In the quantitative part of the paper, we consider a version of the model with i.i.d. human capital shocks and stochastically aging households divided into 9 age groups. Household age affects expected human capital returns and younger households have higher returns than older households. The model is calibrated to be consistent with the U.S. evidence on labor market risk and life-cycle earnings. Specifically, we choose the model parameters determining the life-cycle profile of expected human capital returns so that the implied life-cycle profile of median earnings growth rates matches the data. Further, in our model, i.i.d. shocks to 
the stock of human capital translate into a labor income process that follows a logarithmic random walk; that is, labor income shocks are permanent. The random-walk specification has often been used in the empirical literature to model the permanent component of labor income risk, and we use the estimates obtained by this literature to calibrate our model economy. Finally, for the baseline calibration we use a degree of relative risk aversion of 1 (log-utility) and a level of contract enforcement (exclusion from financial markets in case of default) in line with the US bankruptcy code. The results of our quantitative analysis can be summarized as follows.

First, the calibrated model is in line with the observed life-cycle pattern of household portfolio choices (mix between financial capital and human capital). Second, many young households are borrowing constrained and substantially under-insured, where we measure the degree of consumption insurance by one minus the ratio of the volatility of consumption growth to the volatility of income growth (the insurance coefficient). For example, households of age group 26-30 only insure 40 percent of their human capital risk even though insurance markets exist and are perfectly competitive. Further, the welfare consequences of the lack of consumption insurance are severe. For households of age group 26-30, welfare would increase by 6 percent of lifetime consumption if they had unlimited access to financial markets. Third, the result that many young households are substantially under-insured is robust to realistic variations in the model parameters describing human capital risk, risk aversion, and contract enforcement. However, such parameter variations have non-negligible effects on the extent of equilibrium insurance, which suggest that the model presented here has the potential to account for substantial differences in consumption insurance over time and across countries.

In sum, this paper makes a methodological contribution and a substantive contribution. Theoretically, we develop a general framework and prove a characterization result for recursive equilibria that provides a powerful tool for the quantitative analysis of a wide range 
of interesting macroeconomic issues. Substantively, we show that, contrary to the results obtained by most of the previous literature, limited contract enforcement can explain the observed lack of consumption insurance for a large group of households.

Literature: This paper builds on the large literature on limited commitment/enforcement. See, for example, Alvarez and Jermann (2000), Kehoe and Levine (1993), Kocherlakota (1996), and Thomas and Worrall (1988) for seminal theoretical contributions and Krueger and Perri (2006) and Ligon, Thomas, and Worrall (2002) for highly influential quantitative work. Our theoretical contribution is to develop a tractable model with human capital accumulation and to show how to avoid the non-convexity problem that often arises in limited enforcement models with production. ${ }^{1}$ Our substantive contribution is to show that a calibrated macro model with physical capital and limited contract enforcement generates a substantial degree of underinsurance. In contrast, previous work on consumption insurance in limited enforcement models did not consider life-cycle variations in earnings and human capital investment decisions. As a consequence, in these models there is little reason for households to borrow, and a common finding of the previous literature has been that consumption insurance is almost perfect in calibrated models with physical capital (Cordoba, 2008, and Krueger and Perri, 2006). ${ }^{2}$ Finally, we share with Andolfatto and Gervais (2006) and Lochner and Monge (2011) the focus on human capital accumulation and endogenous borrowing constraints due to enforcement problems, but we go beyond their work by studying the interaction between borrowing constraints and insurance.

The current paper is most closely related to Krebs, Kuhn, and Wright (2015), who pro-

\footnotetext{
${ }^{1}$ Wright (2001) has shown how to circumvent the non-convexity issue in linear production models (AKmodel) with limited enforcement. The model structure we use in this paper is based on the human capital model with incomplete markets analyzed in Krebs (2003).

${ }^{2}$ Krueger and Perri (2006) match the cross-sectional distribution of consumption fairly well, but the implied volatility of individual consumption is negligible in their model.
} 
vide evidence from the life insurance market that human capital returns and insurance are negatively correlated. Krebs, Kuhn, and Wright (2015) also conduct a quantitative analysis of under-insurance based on a calibrated macro model similar to the one studied here. The current analysis goes beyond Krebs, Kuhn, and Wright (2015) in two important dimensions. First, the theoretical results derived in the current paper cover the case of general CRRApreferences, non-steady state behavior, and aggregate risk. In contrast, Krebs, Kuhn, and Wright (2015) confine attention to steady state equilibria in economies with log-preferences and no aggregate risk. Second, in the current paper we provide a comprehensive analysis of the conditions that generate non-negligible under-insurance in calibrated models with limited enforcement and risky human capital investment.

Our paper is also related to the voluminous literature on macroeconomic models with exogenously incomplete markets, and in particular studies of human capital accumulation (Krebs, 2003, Guvenen, Kuruscu, and Ozkan, 2014, and Huggett, Ventura, and Yaron, 2011). The current paper and Krebs, Kuhn, and Wright (2015) are complementary to the incomplete-market literature on human capital investment in the sense that they address similar issues from different angles. Specifically, the incomplete-market approach studies the effect of human capital risk on investment/saving and consumption behavior when no insurance beyond self-insurance is available. In contrast, the limited-enforcement approach analyzes the effect of human capital risk on investment/saving and consumption behavior when insurance markets are available, but endogenous borrowing constraints due to limited contract enforcement generate under-insurance.

\section{Model}

In this section, we develop the model and define the relevant equilibrium concept. The model is a generalization of Krebs, Kuhn, and Wright (2015), which in turn is based on a combination of the human capital model developed in Krebs (2003) and the limited commitment 
model with linear technology presented in Wright $(2001) .^{3}$

\section{a) Human Capital Production}

Time is discrete, open ended, and indexed by $t=0,1, \ldots$ There is a continuum of households who live for a stochastic amount of time. A household who dies is replaced by a new-born household so that the mass of all households alive is normalized to one. We denote the cohort of a household (the period of birth) by $n$, but will suppress the cohort-index for notational ease until we discuss the aggregate market clearing conditions. The exogenous state of an individual household is denoted by $s_{t}$ and has several components $s_{t}=\left(s_{1 t}, \ldots, s_{m t}\right)$. In our quantitative application, $s_{t}$ has two components, one denoting the age of the household and a second representing human capital risk. Depending on the application, additional components can be used to model either ex-ante heterogeneity or ex-post heterogeneity (risk). For example, Krebs, Kuhn, and Wright (2015) use additional components to model the family structure of households in detail. For simplicity, we assume that $s_{t}$ can only take on a finite number of values. We assume that for each household of cohort $n$, the process $\left\{s_{t}\right\}_{t=n}^{\infty}$ is Markov with a stationary transition function and denote the transition probabilities by $\pi\left(s_{t+1} \mid s_{t}\right)$. Note that household variables should in principle have a cohort index $n$ in addition to the time index $t$, but to ease the notation we suppress the cohort index whenever possible.

There is one good that can be consumed or used as physical capital in production (see below). Each household can transform one unit of the good into $\phi\left(s_{t}\right)$ units of human capital. The accumulation equation for human capital, $h$, of an individual household is given by

$$
h_{t+1}=\left(1+\epsilon\left(s_{t-1}, s_{t}\right)\right) h_{t}+\phi\left(s_{t}\right) x_{h t},
$$

\footnotetext{
${ }^{3}$ Angeletos (2007) and Moll (2014) develop tractable models of entrepreneurial activity in which individual consumption/saving policies are linear in wealth. In all these approaches, tractability is achieved through the assumption that individual investment returns are independent of household wealth.
} 
where $x_{h t}$ is human capital investment of the individual household in period $t$ and $\epsilon$ is an idiosyncratic human capital shock.

In line with Jones and Manuelli (1990) and Rebelo (1991), the human capital accumulation equation (1) focuses on the goods cost of human capital production. In contrast, Lucas (1988), Huggett et al. (2011), and Lochner and Monge (2011) assume that the only cost of human capital production is a time cost. As suggested by Ben-Porath (1967) and Trostel (1993), in many applications both goods cost and time cost are important components of the total cost of human capital production. It is straightforward to extend our model to the case that allows for both goods cost and time cost of human capital production (see our discussion in Section III.f below).

The term $\epsilon$ in (1) captures deterministic and random changes in human capital that are due to depreciation, learning-by-doing, and various shocks to human capital (skills) of households. For example, a negative human capital shock could can occur when a household member loses firm- or sector-specific human capital subsequent to job termination (worker displacement). A decline in health (disability) or death of a household member provide further examples of negative human capital shocks. In this case, both general and specific human capital are lost. Internal promotions and upward movement in the labor market provide two examples of positive human capital shocks.

We impose the restriction that the stock of human capital must be non-negative, or $h \geq 0$. This creates no technical difficulty and our general characterization of the household decision rule (proposition 1) holds with this constraint imposed, regardless of whether or not it binds. In our quantitative analysis, this constraint never binds (does not bind for all households types and uncertainty states). We do not impose the requirement that gross human capital investment be non-negative, or $x_{h} \geq 0$. This is necessary for tractability which, in turn, is essential for the theoretical and quantitative analysis conducted in this paper. However, in 
the calibrated model economy used for our quantitative analysis, a number of alternative formulations of non-negativity constraints on human capital investment are always satisfied in equilibrium; that is, they hold for all household types at all ages and all realizations of uncertainty. See the quantitative Section IV for more details. Thus, imposing these restrictions would not change the conclusions drawn in the quantitative analysis.

\section{b) Household Budget Constraint}

An individual household born in period $n$ of type $s_{n}$ begins life with an initial endowment of human capital, $h_{n}$ and an initial endowment of financial assets, $a_{n}$. Thus, the initial state of an individual household is a vector $\left(a_{n}, h_{n}, s_{n}\right)$. In each period $t \geq n$, households can buy and sell a (sequentially) complete set of financial contracts (assets) with state-contingent payoffs, and we assume that for each state $s$ there is one contract or Arrow security. We denote by $a_{t+1}\left(s_{t+1}\right)$ the quantity bought (or sold, if negative) in period $t$ of the contract that pays off one unit of the good in period $t+1$ if $s_{t+1}$ occurs, and denote the price of this contract by $q_{t}\left(s_{t+1}\right)$. A budget-feasible plan has to satisfy the sequential budget constraint

$$
\begin{aligned}
\tilde{r}_{h t} z\left(s_{t}\right) h_{t}+a_{t}\left(s_{t}\right) & =c_{t}+x_{h t}+\sum_{s_{t+1}} a_{t+1}\left(s_{t+1}\right) q_{t}\left(s_{t+1}\right) \\
\sum_{s_{t+1}} a_{t+1}\left(s_{t+1}\right) q_{t}\left(s_{t+1}\right) & \geq-\bar{D} h_{t+1} \\
c_{t} \geq 0, \quad h_{t+1} \geq 0 . &
\end{aligned}
$$

The variable $z$ denotes an idiosyncratic shock to the productivity of human capital while $\tilde{r}_{h t}$ denotes the (common) rental rate per efficiency unit of human capital. The term $\bar{D}<1$ is an explicit debt constraint that requires debt not to exceed the value of human capital. The explicit debt constraint in (2) is sufficient to rule out Ponzi schemes. Since $\bar{D}$ can be chosen arbitrarily close to 1 it amounts to the "natural borrowing constraint" in our setting.

Given the initial state $\left(a_{n}, h_{n}, s_{n}\right)$, a household of cohort $n$ chooses a plan $\left\{c_{t}, a_{t}, h_{t}\right\}_{t=n}^{\infty}$, where each plan is a sequence of functions mapping histories, $s^{n, t}$, into actions, $c_{t}\left(s^{n, t}\right)$, 
$a_{t+1}\left(s^{n, t},.\right)$, and $h_{t+1}\left(s^{n, t}\right)$, where for given $s^{n, t}$ the variable $a_{t+1}\left(s^{n, t},.\right)$ is a vector with components $s_{t+1}$. Here $s^{n, t}=\left(s_{n}, \ldots, s_{t}\right)$ denotes the history of individual states $s_{t}$ from period $n$ up to period $t$. Note that the household level equations (1) and (2) have to hold in realizations; that is, they have to hold for all histories, $s^{n, t}$.

\section{c) Preferences}

Households have identical preferences over consumption plans. Households are risk-averse and their preferences allow for a time-additive expected utility representation:

$$
U\left(\left\{c_{t}\right\}_{t=n}^{\infty} \mid s_{n}\right) \doteq \sum_{t=n}^{\infty} \beta^{t-n} E\left[\nu_{t} u\left(c_{t}\right) \mid s_{n}\right]
$$

where $\nu_{t}$ is the probability that a household born in period $n$ is alive in period $t$ and the expectations is taken over all individual histories

$$
E\left[\nu_{t} u\left(c_{t}\right) \mid s_{n}\right] \doteq \sum_{s^{n, t} \mid s_{n}} \nu_{t}\left(s^{n, t-1}\right) u\left(c_{t}\left(s^{n, t}\right)\right) \pi\left(s^{n, t} \mid s_{n}\right)
$$

Here $\pi\left(s^{n, t} \mid s_{n}\right)$ stands for the history that $s^{n, t}$ occurs given $s_{n}$, which is given by $\pi\left(s^{n, t} \mid s_{n}\right)=$ $\pi\left(s_{n+1} \mid s_{n}\right) \times \ldots\left(s_{t} \mid s_{t-1}\right)$. We assume that $\nu_{t}\left(s^{n, t-1}\right)=\prod_{k=n}^{t-1} \rho\left(s_{k}\right)$, where $\rho\left(s_{k}\right)$ is the survival probability in period $k+1$ of a household who in period $k$ is in state $s_{k}$. Note that survival probabilities depend on age, as encoded in $s_{t}$, but do not depend on cohort. We assume that the one-period utility function exhibits constant relative risk aversion: $u(c)=\frac{c^{1-\gamma}}{1-\gamma}$ for $\gamma \neq 1$ and $u(c)=\ln c$ otherwise. In other words, preferences are homothetic in consumption.

\section{d) Participation/Enforcement Constraint}

We confine attention to equilibria in which households have no incentive to default. Thus, household allocations are required to satisfy the sequential enforcement (or participation) constraints. That is, for all $t \geq n$ and all $s^{n, t}$ we have:

$$
\sum_{m=t}^{\infty} \beta^{m-t} E\left[\nu_{m} u\left(c_{m}\right) \mid s^{n, t}\right] \geq V_{d}\left(h_{t}\left(s^{n, t-1}\right), s_{t}\right)
$$


where $V_{d}$ is the continuation value of a household who decides to default in period $t$. This default value is determined as follows.

We assume that upon default all debts of the household are canceled and all financial assets seized so that $a_{t}\left(s_{t}\right)=0$. While in the default state, households are excluded from purchasing insurance contracts and borrowing (going short). Further, households in default retain their human capital, can invest in human capital, and earn a wage rate $(1-\tau) \tilde{r}_{h}$ per efficiency unit of human capital, where $0 \leq \tau \leq 1$ is a parameter that measures the fraction of labor income that is garnished. Thus, the punishment for default is exclusion from financial markets and possible garnishment of labor income. We assume that households remain in the default state until a stochastically determined future date that occurs with probability $(1-p)$ in each period; that is, the probability of remaining in default is $p$. After moving out of the default state, the household's expected continuation value is $V^{e}$, which depends on $h$ and $s$ at the time of exiting default ( $a=0$ at that point in time). For the individual household the function $V^{e}$ is taken as given, but we close the model and determine this function endogenously by requiring that $V^{e}=V$, where $V$ is the equilibrium value function associated with the maximization problem of a household who participates in financial markets. ${ }^{4}$

In sum, $V_{d}$ is the value function associated with the following household maximization problem

$$
V_{d}\left(h_{t}\left(s^{n, t-1}\right), s_{t}\right) \doteq \max _{\left\{c_{m}, h_{m}\right\}_{m=t}^{\infty}} \sum_{m=t}^{\infty}(p \beta)^{m-t} E\left[\nu_{m} u\left(c_{m}\right) \mid s^{n, t}\right]
$$

${ }^{4}$ The previous literature has usually assumed $p=1$ (permanent autarky). See, however, Krueger and Uhlig (2006) for a model with $p=0$ following a similar approach to ours. Note also that the credit (default) history of an individual household is not a state variable affecting the expected value function, $V^{e}$; we assume that the credit (default) history of households is information that cannot be used for contracting purposes. This is in line with the U.S. bankruptcy code, which limits the history of past behavior that can be retained in credit reports. 


$$
+\sum_{m=t}^{\infty} \beta^{m-t}\left(1-p^{m-t}\right) E\left[\nu_{m} V_{m}^{e}\left(h_{m}\left(s^{n, m-1}\right), s_{m}\right) \mid s^{n, t}\right]
$$

where the continuation plan $\left\{c_{m}, h_{m}\right\}_{m=t}^{\infty}$ has to satisfy the sequential budget constraint

$$
\begin{aligned}
(1-\tau) \tilde{r}_{h, m} z\left(s_{m}\right) h_{m} & =c_{m}+x_{h, m} \\
h_{m+1} & =\left(1+\epsilon\left(s_{m-1}, s_{m}\right)\right) h_{m}+\phi\left(s_{m}\right) x_{h, m} \\
c_{m} \geq 0, h_{m+1} \geq 0 &
\end{aligned}
$$

\section{e) Household Decision Problem}

For given initial state $\left(a_{n}, h_{n}, s_{n}\right)$, a household of cohort $n$ chooses a plan $\left\{c_{t}, a_{t+1}, h_{t+1}\right\}_{t=n}^{\infty}$. The set of budget feasible household plans is defined as

$$
B\left(a_{n}, h_{n}, s_{n}\right) \doteq\left\{\left\{c_{t}, a_{t+1}, h_{t+1}\right\}_{t=n}^{\infty} \mid\left\{c_{t}, a_{t+1}, h_{t+1}\right\}_{t=n}^{\infty} \text { satisfies (1), (2), and (4) }\right\}
$$

The decision problem of a household of initial type $\left(a_{n}, h_{n}, s_{n}\right)$ is

$$
\begin{array}{r}
\max _{\left\{c_{t}, a_{t+1}, h_{t+1}\right\}_{t=n}^{\infty}} U\left(\left\{c_{t}\right\}_{t=n}^{\infty} \mid s_{n}\right) \\
\text { s.t. }\left\{c_{t}, a_{t+1}, h_{t+1}\right\}_{t=n}^{\infty} \in B\left(a_{n}, h_{n}, s_{n}\right)
\end{array}
$$

where the lifetime utility function, $U$, is defined in (3).

\section{f) Goods Production and Physical Capital Accumulation}

There is one good that can be consumed or used as physical capital in production. Production of this good is undertaken by a representative firm that rents capital and labor in competitive markets and uses these input factors to produce output, $Y_{t}$, according to the aggregate production function $Y_{t}=F\left(K_{t}, H_{t}\right)$. Here $K_{t}$ is the aggregate stock of physical capital and $H_{t}$ is the aggregate level of efficiency-weighted human capital employed by the firm.

The aggregate production function, $F$, is a standard neoclassical production function, that is, it has constant-returns-to-scale, satisfies a Inada condition, and is continuous, con- 
cave, and strictly increasing in each argument. Given these assumptions on $F$, the implied intensive-form production function, $f(\tilde{K})=F(\tilde{K}, 1)$, is continuous, strictly increasing, strictly concave, and satisfies a corresponding Inada condition, where we introduced the "capital-to-labor ratio" $\tilde{K}=K / H$. Given the assumption of perfectly competitive labor and capital markets, profit maximization implies

$$
\begin{aligned}
& \tilde{r}_{k t}=f^{\prime}\left(\tilde{K}_{t}\right) \\
& \tilde{r}_{h t}=f\left(\tilde{K}_{t}\right)+f^{\prime}\left(\tilde{K}_{t}\right) \tilde{K}_{t},
\end{aligned}
$$

where $\tilde{r}_{k}$ is the rental rate of physical capital and $\tilde{r}_{h}$ is the rental rate of human capital. Note that $\tilde{r}_{h}$ is simply the wage rate per unit of human capital. Clearly, (7) defines rental rates as functions of the capital-to-labor ratio: $\tilde{r}_{k}=\tilde{r}_{k}(\tilde{K})$ and $\tilde{r}_{h}=\tilde{r}_{h}(\tilde{K})$.

The accumulation equation for the aggregate stock of physical capital is

$$
K_{t+1}=\left(1-\delta_{k}\right) K_{t}+X_{k t}
$$

where $\delta_{k}$ is the depreciation rate of physical capital and $X_{k t}$ is investment in physical capital.

\section{g) Equilibrium}

We confine attention to equilibria in which financial contracts are priced in a risk-neutral manner,

$$
q_{t}\left(s_{t+1}\right)=\frac{\pi\left(s_{t+1} \mid s_{t}\right)}{1+r_{f t}}
$$

where $r_{f}$ is the interest rate on financial transactions, which is equal to the return on physical capital investment, $r_{f t}=\tilde{r}_{k t}-\delta_{k}$. The pricing equation (9) can be interpreted as a zero-profit condition. More precisely, consider financial intermediaries that sell insurance contracts to individual households and invest the proceeds in the risk-free asset that can be created from the complete set of financial contracts and yields a certain return $r_{f}$. Given that financial 
intermediaries face linear investment opportunities and assuming no quantity restrictions on the trading of financial contracts for financial intermediaries, equilibrium requires that financial intermediaries make zero profit, namely condition (9).

Capital market clearing requires that the aggregate stock of physical capital employed by the representative firm is equal to the value of financial wealth held by households. Similarly, labor market clearing requires that the firm's demand for labor equals the aggregate amount of efficiency-weighted human capital supplied by households. More precisely, in equilibrium we have

$$
\begin{aligned}
K_{t+1} & =\sum_{s_{t+1}} \sum_{n=0}^{t} E\left[\nu_{n, t+1} q_{t}\left(s_{t+1}\right) a_{n, t+1}\left(s_{t+1}\right) \mid s_{t+1}\right]+\int_{a_{t+1}} a_{t+1} d \mu_{n e w, t+1}\left(a_{t+1}\right) \\
H_{t+1} & =\sum_{n=0}^{t} E\left[\nu_{n, t+1} z\left(s_{t+1}\right) h_{n, t+1}\right]+\int_{h_{t+1}, s_{t+1}} z\left(s_{t+1}\right) h_{t+1} d \mu_{n e w, t+1}\left(h_{t+1}, s_{t+1}\right),
\end{aligned}
$$

where $\mu_{n e w, t+1}$ is the distribution of new-born households in period $t+1$ over initial states, $\left(a_{t+1}, h_{t+1}, s_{t+1}\right)$, which is an exogenous object. Note that the expectations in (10) is taken over all individual histories and all possible initial states. That is, we define

$$
\begin{gathered}
E\left[\nu_{n, t+1} q_{t+1}\left(s_{t+1}\right) a_{n, t+1}\left(s_{t+1}\right) \mid s_{t+1}\right] \doteq \\
\int_{a_{n}, h_{n}, s_{n}} \sum_{s^{n, t+1} \mid s_{n}} \nu_{n, t+1}\left(s^{n, t}\right) q_{t}\left(s_{t+1} ; s_{t}\right) a_{n, t+1}\left(s_{t+1} ; s^{n, t}, a_{n}, h_{n}, s_{n}\right) \pi\left(s^{n, t} \mid s_{n}\right) d \mu_{n e w, n}\left(a_{n}, h_{n}, s_{n}\right)
\end{gathered}
$$

and

$$
\begin{gathered}
E\left[\nu_{n, t+1} z\left(s_{t+1}\right) h_{n, t+1}\right] \stackrel{\doteq}{\int_{a_{n}, h_{n}, s_{n}} \sum_{s^{n, t+1} \mid s_{n}} \nu_{n, t+1}\left(s^{n, t}\right) z\left(s_{t+1}\right) h_{n, t+1}\left(s^{n, t}, a_{n}, h_{n}, s_{n}\right) \pi\left(s^{n, t+1} \mid s_{n}\right) d \mu_{n e w, n}\left(a_{n}, h_{n}, s_{n}\right)}
\end{gathered}
$$

Note that we allow the distributions of new-born households, $\mu_{n e w, n}$, to depend on the cohort $n$ in order to be permit an endogenous growth path.

The distribution $\mu_{n e w, n}$ has to satisfy an aggregate resource restriction. Specifically, we assume that the aggregate stock of physical capital (human capital) of new-born households 
is proportional to the aggregate stock of physical capital (human capital) of households who have died:

$$
\int_{a_{n^{\prime}+1}} a_{n^{\prime}+1} d \mu_{n e w, n^{\prime}+1}\left(a_{n^{\prime}+1}\right)=
$$

$\lambda_{a} \sum_{n=0}^{n^{\prime}} \int_{a_{n}, h_{n}, s_{n}} \sum_{s^{n, n^{\prime}}}\left(1-\rho\left(s_{n^{\prime}}\right)\right) \nu_{n, n^{\prime}}\left(s^{n, n^{\prime}-1}\right) a_{n, n^{\prime}+1}\left(s^{n, n^{\prime}}, a_{n}, h_{n}, s_{n}\right) \pi\left(s^{n, n^{\prime}} \mid s_{n}\right) d \mu_{n e w, n}\left(a_{n}, h_{n}, s_{n}\right)$ and

$$
\begin{gathered}
\int_{h_{n^{\prime}+1}} h_{n^{\prime}+1} d \mu_{n e w, n^{\prime}+1}\left(h_{n^{\prime}+1}\right)= \\
\lambda_{h} \sum_{n=0}^{n^{\prime}} \int_{a_{n}, h_{n}, s_{n}} \sum_{s^{n, n^{\prime}}} \rho\left(s_{n^{\prime}}\right) \nu_{n, n^{\prime}}\left(s^{n, n^{\prime}-1}\right) h_{n^{\prime}+1}\left(s^{n, n^{\prime}}, a_{n}, h_{n}, s_{n}\right) \pi\left(s^{n, n^{\prime}} \mid s_{n}\right) d \mu_{n e w, n}\left(a_{n}, h_{n}, s_{n}\right)
\end{gathered}
$$

where $\lambda_{a}$ is a parameter that measures the relationship between physical capital of households born in period $n^{\prime}+1$ relative to the physical capital of households who leave the model in period $n^{\prime}+1$. These parameters summarize to what extent physical capital is passed on to the next generation and to what extent a new-born generation starts with additional capital unrelated to the capital of their parents/grandparents. In most cases, we have $\lambda_{a}=1$ (closed economy), but other cases are possible. The parameter $\lambda_{h}$ expresses the size of human capital of new-born households relative to the aggregate stock of human capital in the economy. Equation (11) imposes a restriction on the exogenous distributions $\mu_{n e w, n}$.

The aggregate resource constraint states that total output produced is equal to aggregate consumption plus aggregate investment

$$
Y_{t}=C_{t}+X_{k t}+X_{h t}
$$

where $X_{k t}$ is aggregate investment in physical capital and $X_{h t}$ is aggregate investment in human capital. As in (10), we compute aggregate variables from the respective household-level variables by summing over cohorts and averaging over individual histories and possible initial states. It is straightforward to show that the capital and labor market clearing conditions (10) in conjunction with the household budget constraint (2) and the capital accumulation 
equations (1) and (8) imply the goods market clearing condition (12) using the asset pricing formula (9). In our equilibrium analysis we will use focus on the two market clearing conditions in (10), which can be subsumed to one market clearing condition because of the constant-returns-to-scale assumption (see below).

Our definition of a sequential equilibrium is standard:

Definition 1 A sequential equilibrium is a sequence of aggregate stocks of physical capital and (productivity weighted) human capital, $\left\{K_{t}, H_{t}\right\}$, rental rates, $\left\{\tilde{r}_{k t}, \tilde{r}_{h t}\right\}$, and a family of household plans, $\left\{c_{t}, a_{t}, h_{t}\right\}_{t=n}^{\infty}$, one for each cohort $n$ and initial household type $\left(a_{n}, h_{n}, s_{n}\right)$, so that

i) Utility maximization of households: for each initial state, $\left(a_{n}, h_{n}, s_{n}\right)$, the plan $\left\{c_{t}, a_{t}, h_{t}\right\}_{t=n}^{\infty}$ solves the household problem (6).

ii) Profit maximization of firms: $\left(K_{t}, H_{t}\right)$ maximizes profit for all $t$, that is, the aggregate capital-to-labor ratio, $\tilde{K}_{t}$, and rental rates, $\tilde{r}_{k t}$ and $\tilde{r}_{h t}$ satisfy the first-order conditions (7) for all $t$.

iii) Profit maximization of financial intermediaries: financial contracts are priced according to (9).

iv) Market clearing in capital and labor markets: equation (10) holds.

v) Rational expectations: expected continuation value functions are equal to actual continuation value functions: $V^{e}=V$.

We next turn to the characterization of equilibria. 


\section{Theoretical Results}

In this section, we state the two main theoretical results. First, the solution to the individual household maximization problem is linear in total individual wealth (financial and human). This partial equilibrium result is stated in proposition 2 and the proof is based on a monotone operator argument (proposition 1). Second, the distribution of total wealth (financial plus human), $\Omega$, over household types, $s$, is a sufficient aggregate state variable. This general equilibrium result is stated in proposition 3. We begin this section with a discussion of a convenient change of variables and a definition of recursive equilibria with aggregate state $\Omega$.

\section{a) Change of Variables}

For the characterization of equilibria, it is convenient to introduce new variables that emphasize the fact that individual households solve a standard inter-temporal portfolio choice problem (with additional participation constraints). To this end, introduce the following variables:

$$
\begin{aligned}
\tilde{w}_{t} & =\frac{h_{t}}{\phi\left(s_{t}\right)}+\sum_{s_{t}} q_{t-1}\left(s_{t}\right) a_{t}\left(s_{t}\right) \\
\theta_{h t} & =\frac{h_{t}}{\phi\left(s_{t}\right) w_{t}}, \theta_{a t}\left(s_{t}\right)=\frac{a_{t}\left(s_{t}\right)}{w_{t}} \\
1+r\left(\theta_{t}, s_{t-1}, s_{t}\right) & = \begin{cases}\left(1+r_{h t}\left(s_{t-1}, s_{t}\right)\right) \theta_{h t}+\theta_{a t}\left(s_{t}\right) & \text { if no default } \\
\left(1+r_{h d, t}\left(s_{t-1}, s_{t}\right)\right) \theta_{h t} & \text { if default }\end{cases}
\end{aligned}
$$

where $r_{h t}\left(s_{t-1}, s_{t}\right) \doteq z\left(s_{t}\right) \phi\left(s_{t}\right) \tilde{r}_{h t}+\epsilon\left(s_{t-1}, s_{t}\right)$ is the return on human capital investment if the household does not default and $r_{h d, t}\left(s_{t-1}, s_{t}\right) \doteq(1-\tau) z\left(s_{t}\right) \phi\left(s_{t}\right) \tilde{r}_{h t}+\epsilon\left(s_{t-1}, s_{t}\right)$ is the return on human capital investment in case of default. In (13) the variable $\tilde{w}_{t}$ stands

for beginning-of-period wealth consisting of the value of human wealth, $\frac{h_{t}}{\phi\left(s_{t}\right)}$, and financial wealth, $\sum_{s_{t}} q_{t-1}\left(s_{t}\right) a_{t}\left(s_{t}\right)$. The variable $\theta_{t}=\left(\theta_{h t}, \theta_{a t}\right)$ denotes the vector of portfolio shares and $(1+r)$ is the total return to investment. Recall that for given history of shocks, $\theta_{h t}$ 
is a number, but $\theta_{a t}$ is a vector with components $\theta_{a t}\left(s_{t}\right)$. Using the new notation and substituting out the investment variables, $x_{k t}$ and $x_{h t}$, the budget constraint (2) and human capital accumulation equation (1) read

$$
\begin{aligned}
\tilde{w}_{t+1}= & \left(1+r\left(\theta_{t}, s_{t-1}, s_{t}\right)\right) \tilde{w}_{t}-c_{t} \\
1= & \theta_{h, t+1}+\sum_{s_{t+1}} q_{t}\left(s_{t+1}\right) \theta_{a, t+1}\left(s_{t+1}\right) \\
& \sum_{s_{t+1}} q_{t}\left(s_{t+1}\right) \theta_{a, t+1}\left(s_{t+1}\right) \geq \bar{D} \theta_{h, t+1} \\
c_{t} \geq & 0, \tilde{w}_{t+1} \geq 0, \quad \theta_{h, t+1} \geq 0 .
\end{aligned}
$$

Clearly, (14) is the budget constraint corresponding to an inter-temporal portfolio choice problem with linear investment opportunities and no exogenous source of income.

It is convenient to use as individual state variable wealth including current asset payoffs ("cash at hand") defined as $w_{t} \doteq\left(1+r_{t}\right) \tilde{w}_{t}$. Using this concept of total wealth, the budget constraint (14) can be written as

$$
\begin{aligned}
w_{t+1}= & \left(1+r\left(\theta_{t+1}, s_{t}, s_{t+1}\right)\right)\left(w_{t}-c_{t}\right) \\
1= & \theta_{h, t+1}+\sum_{s_{t+1}} q_{t}\left(s_{t+1}\right) \theta_{a, t+1}\left(s_{t+1}\right) \\
& \sum_{s_{t+1}} q_{t}\left(s_{t+1}\right) \theta_{a, t+1}\left(s_{t+1}\right) \geq \bar{D} \theta_{h, t+1} \\
c_{t} \geq & 0, w_{t+1} \geq 0, \quad \theta_{h, t+1} \geq 0 .
\end{aligned}
$$

Further, the default value function, $V_{d}$, can be written as a function of $w$, and $(w, s)$ is therefore a sufficient state for the enforcement constraint (4). Thus, the household maximization problem (6) is equivalent to the household maximization problem

$$
\begin{array}{r}
\max _{\left\{c_{t}, w_{t+1}, \theta_{t+1}\right\}_{t=n}^{\infty}} U\left(\left\{c_{t}\right\}_{t=n}^{\infty} \mid s_{n}\right) \\
\text { s.t. }\left\{c_{t}, w_{t+1}, \theta_{t+1}\right\}_{t=n}^{\infty} \in B\left(w_{n}, s_{n}\right)
\end{array}
$$

where the budget set is now defined as

$$
B\left(w_{n}, s_{n}\right) \doteq\left\{\left\{c_{t}, w_{t+1}, \theta_{t+1}\right\}_{t=n}^{\infty} \mid\left\{c_{t}, w_{t+1}, \theta_{t+1}\right\}_{t=n}^{\infty} \text { satisfies (4) and (15) }\right\}
$$




\section{b) Recursive Equilibrium: Definition}

We next define a recursive equilibrium. To this end, we first note that the market clearing condition (10) can be reduced to the condition

$$
\tilde{K}_{t+1}=\frac{\sum_{s_{t+1}} \sum_{n=0}^{t} E\left[\nu_{n, t+1} q_{t}\left(s_{t+1}\right) a_{n, t+1}\left(s_{t+1}\right) \mid s_{t+1}\right]+\int_{a_{t+1}} a_{t+1} d \mu_{n e w, t+1}\left(a_{t+1}\right)}{\sum_{n=0}^{t} E\left[\nu_{n, t+1} z\left(s_{t+1}\right) h_{n, t+1}\right]+\int_{h_{t+1}, s_{t+1}} z\left(s_{t+1}\right) h_{t+1} d \mu_{n e w, t+1}\left(h_{t+1}, s_{t+1}\right)}
$$

because of the constant-return assumption. In a sequential equilibrium, the expectations in (17) is taken over all individual histories and all initial states, and it depends in general explicitly on time $t$. In a recursive equilibrium, the expectations is taken over individual states conditional on the aggregate state, and it is time-independent.

The household maximization problem (16) suggests that we can use $(w, s)$ as the individual state variable. For the aggregate state, in general the distribution, $\mu$, over individual states, $(w, s)$, is the minimal state variable. However, for the current model, the typedependent wealth distribution, $\Omega \in \mathbb{R}^{n}$, defined as

$$
\Omega_{t}\left(s_{t}\right) \doteq \frac{E\left[\sum_{n=0}^{t} \nu_{n, t} w_{n, t} \mid s_{t}\right]}{E\left[\sum_{n=0}^{t} \nu_{n, t} w_{n, t}\right]} .
$$

turns out to be sufficient (see below). Here $\Omega_{t}\left(s_{t}\right)$ is the share of aggregate total wealth owned by all households of type $s_{t}$. Note that $\Omega$ is a distribution since $E\left[\Omega_{t}\right]=\sum_{s_{t}} \Omega_{t}\left(s_{t}\right)=1$. Note further that the distribution $\mu$ is an infinite-dimensional object, whereas the distribution $\Omega$ is finite-dimensional.

Below we construct a recursive equilibrium with aggregate state variable $\Omega$ that evolves according to an endogenous law of motion $\Omega^{\prime}=\Phi(\Omega)$, where the prime denotes next period's variable. We further show that next period's optimal portfolio choice is independent of $w$, which implies that the market clearing condition (17) becomes a condition that defines a function $\tilde{K}^{\prime}=\tilde{K}^{\prime}(\Omega)$. Together with the first-order conditions (7) this defines rental rate functions $\tilde{r}_{k}^{\prime}=\tilde{r}_{k}^{\prime}(\Omega)$ and $\tilde{r}_{h}^{\prime}=\tilde{r}_{h}^{\prime}(\Omega)$. Given our definition of sequential equilibrium and the variables defined so far, our definition of recursive equilibrium is standard: 
Definition 2 A recursive equilibrium is a law of motion, $\Phi$, for the aggregate state variable, $\Omega$, a function $\tilde{K}^{\prime}=\tilde{K}^{\prime}(\Omega)$, rental rate functions $\tilde{r}_{k}^{\prime}=\tilde{r}_{k}^{\prime}(\Omega)$ and $\tilde{r}_{h}^{\prime}=\tilde{r}_{h}^{\prime}(\Omega)$, an expected value function, $V^{e}$, and a household policy function, $g,{ }^{5}$ such that

i) Utility maximization of households: for all household cohorts, $n$, and household types, $\left(w_{n}, s_{n}\right)$, the household policy function, $g$, in conjunction with the law of motion, $\Phi$, generates a plan, $\left\{c_{t}, w_{t+1}, \theta_{t+1}\right\}_{t=n}^{\infty}$, that solves the household maximization problem (16).

ii) Profit maximization of firms: for any sequence $\{\tilde{K}\}_{t=0}^{\infty}$, the rental rate sequences $\left\{\tilde{r}_{k t}\right\}_{t=0}^{\infty}$ and $\left\{\tilde{r}_{h t}\right\}_{t=0}^{\infty}$ are defined by the first-order conditions (7).

iii) Profit maximization of financial intermediaries: financial contracts are priced according to $(9)$

iv) Market clearing: for any initial state $\Omega$, the law of motion $\Phi$ in conjunction with the function $\tilde{K}^{\prime}$ generate a sequence $\{\tilde{K}\}_{t=0}^{\infty}$ that satisfies the market clearing condition (17)

v) Rational expectations: $V^{e}=V$ and $\Phi$ is the law of motion induced by $g$.

\section{c) Characterization of Household Problem (Partial Equilibrium)}

The principle of optimality in conjunction with our discussion in the previous section regarding the appropriate aggregate state suggest that the household maximization problem (16) is equivalent to the Bellman equation

$$
\begin{aligned}
V(w, s, \Omega)= & \max _{c, w^{\prime}, \theta^{\prime}}\left\{u(c)+\beta \rho(s) \sum_{s^{\prime}} V\left(w^{\prime}, s^{\prime}, \Omega^{\prime}\right) \pi\left(s^{\prime} \mid s\right)\right\} \\
\text { s.t. } & w^{\prime}=\left(1+r\left(\theta^{\prime}, s, s^{\prime}, \Omega\right)\right)(w-c) \\
& 1=\theta_{h}^{\prime}+\sum_{s^{\prime}} \frac{\pi\left(s^{\prime} \mid s\right) \theta_{a}^{\prime}\left(s^{\prime}\right)}{1+r_{f}(\Omega)} \\
& \sum_{s^{\prime}} \frac{\pi\left(s^{\prime} \mid s\right) \theta_{a}^{\prime}\left(s^{\prime}\right)}{1+r_{f}(\Omega)} \geq-\bar{D} \theta_{h}^{\prime}, \theta_{h}^{\prime} \geq 0, \quad w^{\prime} \geq 0
\end{aligned}
$$

${ }^{5}$ The function $g$ defines next period's endogenous state as a function of this period's endogenous state and this period's exogenous shock: $w_{t+1}=g\left(w_{t}, s_{t}\right)$. 


$$
\begin{aligned}
& V\left(w^{\prime}, s^{\prime}, \Omega^{\prime}\right) \geq V_{d}\left(w^{\prime}, s^{\prime}, \Omega^{\prime}\right) \\
& \Omega^{\prime}=\Phi(\Omega)
\end{aligned}
$$

where the default value function is given by

$$
\begin{aligned}
V_{d}(w, s, \Omega)= & \max _{c, w^{\prime}}\left\{u(c)+\beta \rho(s) p \sum_{s^{\prime}} \rho\left(s^{\prime}\right) V_{d}\left(w^{\prime}, s^{\prime}, \Omega^{\prime}\right) \pi\left(s^{\prime} \mid s\right)\right. \\
& \left.+\beta \rho(s)(1-p) \sum_{s^{\prime}} V^{e}\left(w^{\prime}, s^{\prime}, \Omega^{\prime}\right) \pi\left(s^{\prime} \mid s\right)\right\} \\
& w^{\prime}=\left(1+r_{h d}\left(s, s^{\prime}, \Omega\right)\right)(w-c) \\
& \Omega^{\prime}=\Phi(\Omega)
\end{aligned}
$$

Let $T$ be the operator associated with the Bellman equation (18). In contrast to the standard case without a participation constraint, the Bellman operator, $T$, defined by equation (18) is in general not a contraction. However, it is still a monotone operator. Monotone operators might have multiple fixed points, but under certain conditions we can construct a sequence that converges to the maximal element of the set of fixed points. This maximal solution is also the value function (principle of optimality). More precisely, if the condition that for all $s$

$$
\begin{aligned}
& \forall \theta^{\prime}: \beta \rho(s) \sum_{s^{\prime}}\left(1+r\left(\theta^{\prime}, s, s^{\prime}, \Omega^{\prime}\right)\right)^{1-\gamma} \pi\left(s^{\prime} \mid s\right)<1 \text { if } 0<\gamma<1 \\
& \exists \theta^{\prime}: \beta \rho(s) \sum_{s^{\prime}}\left(1+r\left(\theta^{\prime}, s, s^{\prime}, \Omega^{\prime}\right)\right)^{1-\gamma} \pi\left(s^{\prime} \mid s\right)<1 \text { if } \gamma>1
\end{aligned}
$$

holds ${ }^{6}$ then we have the following results:

Proposition 1. Suppose that condition (19) is satisfied and that the law of motion, $\Phi$, and the value function of a household in financial autarky, $V_{d}$, are continuous. Let $T$ stand for the operator associated with the Bellman equation (18). Then

${ }^{6}$ Note that for the log-utility case, no condition of the type (19) is required. 
i) There is a unique continuous solution, $V_{0}$, to the Bellman equation (18) without participation constraint.

ii) $\lim _{k \rightarrow \infty} T^{k} V_{0}=V_{\infty}$ exists and is the maximal solution to the Bellman equation (18)

iii) $V_{\infty}$ is the value function, $V$, of the sequential household maximization problem.

Proof. See Appendix.

Consider the case $V^{e}=V$. Using proposition 2 and an induction argument, we can then show that the value function, $V$, has the functional form

$$
V(w, s, \Omega)= \begin{cases}\tilde{V}(s, \Omega) w^{1-\gamma} & \text { if } \gamma \neq 1 \\ \tilde{V}_{0}(s, \Omega)+\tilde{V}_{1}(s) \ln w & \text { otherwise }\end{cases}
$$

and that the corresponding optimal policy function, $g$, is

$$
\begin{aligned}
c(w, s) & =\tilde{c}(s, \Omega) w \\
w^{\prime}\left(w, s, s^{\prime}, \Omega\right) & =\left(1+r\left(\theta^{\prime}, s, s^{\prime}, \Omega\right)\right)(1-\tilde{c}(s, \Omega)) w \\
\theta^{\prime}(w, s, \Omega) & =\theta^{\prime}(s, \Omega) .
\end{aligned}
$$

In other words, the value function has the functional form of the underlying utility function, consumption and next-period wealth are linear functions of current period wealth, and nextperiod portfolio choices are independent of wealth. Moreover, we also show that the intensiveform value function, $\tilde{V}$, together with the optimal consumption and portfolio choices, $\tilde{c}$ and $\theta$, can be found by solving an intensive-form Bellman equation that reads

$$
\begin{aligned}
\tilde{V}(s, \Omega)= & \max _{\tilde{c}, \theta^{\prime}}\left\{\frac{\tilde{c}^{1-\gamma}}{1-\gamma}+\beta \rho(s)(1-\tilde{c})^{1-\gamma} \sum_{s^{\prime}}\left(1+r\left(\theta^{\prime}, s, s^{\prime}, \Omega\right)\right)^{1-\gamma} \tilde{V}\left(s^{\prime}, \Omega^{\prime}\right) \pi\left(s^{\prime} \mid s\right)\right\} \\
\text { s.t. } \quad 1=\theta_{h}^{\prime}+\sum_{s^{\prime}} \frac{\theta_{a}^{\prime}\left(s^{\prime}\right) \pi\left(s^{\prime} \mid s\right)}{1+r_{f}(\Omega)} & \\
& \sum_{s^{\prime}} \frac{\pi\left(s^{\prime} \mid s\right) \theta_{a}^{\prime}\left(s^{\prime}\right)}{1+r_{f}(\Omega)} \geq-\bar{D} \theta_{h}^{\prime}, \quad \theta_{h}^{\prime} \geq 0,0 \leq \tilde{c} \leq 1
\end{aligned}
$$




$$
\begin{aligned}
& \left(\frac{\tilde{V}\left(s^{\prime}, \Omega^{\prime}\right)}{\tilde{V}_{d}\left(s^{\prime}, \Omega^{\prime}\right)}\right)^{\frac{1}{1-\gamma}}\left(1+r\left(\theta^{\prime}, s, s^{\prime}, \Omega\right)\right) \geq\left(1+r_{h d}\left(s, s^{\prime}, \Omega\right)\right) \theta_{h}^{\prime} \\
& \Omega^{\prime}=\Phi(\Omega)
\end{aligned}
$$

and

$$
\begin{aligned}
\tilde{V}_{d}(s, \Omega)= & \max _{\tilde{c}_{d}}\left\{\frac{\tilde{c}_{d}^{1-\gamma}}{1-\gamma}+p \beta \rho(s)\left(1-\tilde{c}_{d}\right)^{1-\gamma} \sum_{s^{\prime}}\left(1+r_{h d}\left(s, s^{\prime}, \Omega\right)\right)^{1-\gamma} \tilde{V}_{d}\left(s^{\prime}, \Omega^{\prime}\right) \pi\left(s^{\prime} \mid s\right)\right. \\
& \left.(1-p) \beta \rho(s)\left(1-\tilde{c}_{d}\right)^{1-\gamma} \sum_{s^{\prime}}\left(1+r_{h d}\left(s, s^{\prime}, \Omega\right)\right)^{1-\gamma} \tilde{V}\left(s^{\prime}, \Omega^{\prime}\right) \pi\left(s^{\prime} \mid s\right)\right\}
\end{aligned}
$$

for $\gamma \neq 1$. In the case of log-utility, the intensive-form Bellman equation reads

$$
\begin{aligned}
\tilde{V}_{0}(s, \Omega)= & \max _{\tilde{c}, \theta^{\prime}}\left\{\ln \tilde{c}+\beta \rho(s) \sum_{s^{\prime}} \tilde{V}_{0}\left(s^{\prime}\right) \pi\left(s^{\prime} \mid s\right)+\beta \rho(s) \ln (1-\tilde{c}) \sum_{s^{\prime}} \tilde{V}_{1}\left(s^{\prime}\right) \pi\left(s^{\prime} \mid s\right)\right. \\
& \left.+\beta \rho(s) \sum_{s^{\prime}} \tilde{V}_{1}\left(s^{\prime}\right) \ln \left(1+r\left(\theta^{\prime}, s, s^{\prime}, \Omega\right)\right) \pi\left(s^{\prime} \mid s\right)\right\} \\
\text { s.t. } \quad & =\theta_{h}^{\prime}+\sum_{s^{\prime}} \frac{\theta_{a}^{\prime}\left(s^{\prime}\right) \pi\left(s^{\prime} \mid s\right)}{1+r_{f}(\Omega)} \\
& \sum_{s^{\prime}} \frac{\pi\left(s^{\prime} \mid s\right) \theta_{a}^{\prime}\left(s^{\prime}\right)}{1+r_{f}(\Omega)} \geq-\bar{D} \theta_{h}^{\prime}, \theta_{h}^{\prime} \geq 0 \\
& e^{(1-\beta)\left(\tilde{V}_{0}\left(s^{\prime}, \Omega^{\prime}\right)-\tilde{V}_{d 0}\left(s^{\prime}, \Omega^{\prime}\right)\right)}\left(1+r\left(\theta^{\prime}, s, s^{\prime}, \Omega\right)\right) \geq\left(1+r_{h d}\left(s, s^{\prime}, \Omega\right)\right) \theta_{h}^{\prime} \\
& \Omega^{\prime}=\Phi(\Omega)
\end{aligned}
$$

and

$$
\begin{aligned}
\tilde{V}_{0 d}(s, \Omega)= & \max _{\tilde{c}_{d}}\left\{\ln \tilde{c}_{d}+\beta \ln \left(1-\tilde{c}_{d}\right) \sum_{s^{\prime}} \tilde{V}_{1}\left(s^{\prime}\right) \rho\left(s^{\prime}\right) \pi\left(s^{\prime} \mid s\right)\right. \\
& +\beta \rho(s) \sum_{s^{\prime}} \tilde{V}_{1}\left(s^{\prime}\right) \ln \left(1+r_{h d}\left(s, s^{\prime}, \Omega\right)\right) \pi\left(s^{\prime} \mid s\right) \\
& \left.+p \beta \rho(s) \sum_{s^{\prime}} \tilde{V}_{0 d}\left(s^{\prime}\right) \pi\left(s^{\prime} \mid s\right)+(1-p) \beta \rho(s) \sum_{s^{\prime}} \tilde{V}_{0}\left(s^{\prime}\right) \pi\left(s^{\prime} \mid s\right)\right\}
\end{aligned}
$$


where the coefficients $\tilde{V}_{1}$ are the solution to

$$
\tilde{V}_{1}(s)=1+\beta \rho(s) \sum_{s^{\prime}} \tilde{V}_{1}\left(s^{\prime}\right) \pi\left(s^{\prime} \mid s\right)
$$

Proposition 2. Suppose that condition (19) is satisfied, the law of motion, $\Phi$, is continuous, and $V^{e}=V$. Then value function, $V$, and optimal policy function, $g$, have the functional form (20). Moreover, the intensive-form value function, $\tilde{V}$, and the corresponding optimal consumption and portfolio choices, $\tilde{c}$ and $\theta^{\prime}$, are the maximal solution to the intensive-form Bellman equation (21). This maximal solution is obtained by iteratively applying $\tilde{T}$, the operator associated with the intensive-form Bellman equation (21), starting from $\tilde{V}_{0}$, the solution of the intensive-form Bellman equation (22) without participation constraint:

$$
\tilde{V}=\lim _{n \rightarrow \infty} \tilde{T}^{n} \tilde{V}_{0}
$$

Proof. See Appendix.

Note that proposition 2 cannot simply be proved by the guess-and-verify method since multiple solutions to the Bellman equation (21) may exist. Specifically, the operator associated with the Bellman equation is monotone, but not a contraction, and hence multiple fixed points may exist. However, proposition 2 ensures that we have indeed found the value function associated with the original utility maximization problem, and also provides us with a iterative method to compute this solution. Note further that the constraint set in (21) is linear since the return functions are linear in $\theta$. Thus, the constraint set is convex and we have transformed the original utility maximization problem into a convex problem. In other words, the non-convexity problem alluded to in the introduction has been resolved.

\section{d) Characterization of Recursive Equilibria}

Proposition 2 shows how to rewrite the maximization problem of individual households as a recursive problem that is wealth-independent. One implication of the intensive-form 
representation of the individual maximization problem is that optimal portfolio choices are independent of wealth, $w$. This result in turn implies that the market clearing condition (17) can be re-written as

$$
\tilde{K}^{\prime}=\frac{\sum_{s}\left[\rho(s)+\lambda_{a}(1-\rho(s))\right]\left(1-\theta_{h}(s, \Omega)\right)(1-\tilde{c}(s, \Omega)) \Omega(s)}{\bar{z} \sum_{s}\left[\rho(s)+\lambda_{h}\right] \phi(s) \theta_{h}(s, \Omega)(1-\tilde{c}(s, \Omega)) \Omega(s)}
$$

where we have already incorporated restriction (11) and $\bar{z}$ stands for the mean of $z$. Equation (22) defines a function $\tilde{K}^{\prime}=\tilde{K}^{\prime}(\Omega)$, which in turn defines rental rate functions $\tilde{r}_{k}^{\prime}=\tilde{r}_{k}^{\prime}(\Omega)$ and $\tilde{r}_{h}^{\prime}=\tilde{r}_{h}^{\prime}(\Omega)$ using the first-order conditions (7). A second implication of proposition 2 is that the equilibrium law of motion, $\Phi$, can be explicitly derived:

$$
\Omega^{\prime}\left(s^{\prime}\right)=\frac{\sum_{s} \rho(s)(1-\tilde{c}(s, \Omega))\left(1+r\left(\theta^{\prime}(s, \Omega), s^{\prime}, \Omega\right)\right) \pi\left(s^{\prime} \mid s\right) \Omega(s)+\lambda \Omega_{n e w}^{\prime}\left(s^{\prime}\right)}{\sum_{s, s^{\prime}} \rho(s)(1-\tilde{c}(s, \Omega))\left(1+r\left(\theta^{\prime}(s, \Omega), s^{\prime}, \Omega\right)\right) \pi\left(s^{\prime} \mid s\right) \Omega(s)+\lambda}
$$

where the parameter $\lambda$ is related to the parameters $\lambda_{a}$ and $\lambda_{h}$ through the restriction (11). Note that the expression in the denominator of (23) ensures that $\sum_{s^{\prime}} \Omega^{\prime}\left(s^{\prime}\right)=1$.

In sum, a recursive equilibrium can be found by solving (21) and (22), and using (23) as the law of motion:

Proposition 3. Suppose that $\left(\theta, \tilde{c}, \tilde{V}, \tilde{K}^{\prime}\right)$ is an intensive-form equilibrium, that is, $\left(\theta, \tilde{c}, \tilde{V}, \tilde{K}^{\prime}\right)$ solves $(21)$ and $(22)$. Then $\left(g, \tilde{V}, \tilde{K}^{\prime}, \Phi\right)$ is a recursive equilibrium, where $g$ is the individual policy function associated with $(\theta, \tilde{c})$ and $\Phi$ the aggregate law of motion defined in (23). Proof. See Appendix.

Proposition 3 simplifies the computation of recursive equilibria. In our framework, the infinite-dimensional wealth distribution is not a relevant state variable. Instead, the distribution of wealth shares over household types, $\Omega$, becomes a relevant state variable. Note that $\Omega$ is in many applications a low-dimensional object. For example, suppose that $s_{t}=\left(s_{1 t}, s_{2 t}\right)$, where $\left\{s_{1 t}\right\}$ and $\left\{s_{2 t}\right\}$ are two independent processes and $\left\{s_{2 t}\right\}$ is an i.i.d process. In this case neither $\tilde{c}$ nor $\theta$ depend on $s_{2}$ and the relevant aggregate state is $\Omega\left(s_{1}\right)$ only. 


\section{e) Extension: Aggregate Shocks}

So far, we have considered economies with only idiosyncratic risk, but it is straightforward to introduce aggregate risk into the framework. To this end, suppose that there are idiosyncratic shocks, $s$, and aggregate shocks, $S$, and that uncertainty is described by a stationary joint Markov process $\left\{s_{t}, S_{t}\right\}$ with transition probabilities denoted by $\pi\left(s_{t+1}, S_{t+1} \mid s_{t}, S_{t}\right)$. The relevant aggregate state then becomes $\left(\Omega_{t}, S_{t}\right)$, where $\Omega_{t}$ is defined as before. In a recursive equilibrium, the evolution of the endogenous aggregate state variable is given by an endogenous law of motion $\Omega_{t+1}=\Phi\left(\Omega_{t}, S_{t}, S_{t+1}\right)$. Further, the aggregate capital-to-labor

ratio is a function $\tilde{K}_{t+1}\left(\Omega_{t}, S_{t}\right)$ and the rentals rates are function $\tilde{r}_{k, t+1}=\tilde{r}_{k}\left(\Omega_{t}, S_{t}\right)$ and $\tilde{r}_{h, t+1}=\tilde{r}_{h}\left(\Omega_{t}, S_{t}\right)$. The definition of a recursive equilibrium is, mutatis mutandis, as before.

A straightforward (though lengthy) extension of the subsequent theoretical analysis shows that a modified version of our general characterization results still hold. In particular, recursive equilibria can be computed by solving a convex problem that is independent of the wealth distribution, though clearly the finite-dimensional distribution of relative wealth, $\Omega$, still enters into the equilibrium conditions.

\section{f) Further Extensions}

There a several further extensions of the model that can be incorporated without sacrificing the tractability of the model. First, we can introduce a time cost in human capital production if we replace the term $\phi\left(s_{t}\right) x_{h t}$ in $(1)$ by $\phi\left(s_{t}\right)\left(h_{t} l_{h t}\right)^{\alpha} x_{h t}^{1-\alpha}$, where $l_{h t}$ is the time spent in human capital production. In the simplest extension, the household allocates time between working and producing human capital (learning). However, we can also add a labor-leisure choice as long as preferences remain homothetic in consumption. It is straightforward to show that the human capital production function $\phi\left(s_{t}\right)\left(h_{t} l_{h t}\right)^{\alpha} x_{h t}^{1-\alpha}$ gives rise to a human capital accumulation equation (1) that is still linear in $x_{h t}$ after the optimal choice of $l_{h t}$ has 
been substituted out.

A second extension is shocks to preferences (taste shocks, health shocks, change in family structure). These can easily be incorporated by replacing the one-period utility function by one that depends on the state $s_{t}$. Third, the tractability is preserved in a model with taxes and transfers as long as these payments are proportional to either financial capital (capital income) or human capital (labor income). To see this, simply re-define the returns in (13) as returns after taxes and transfers have been taken into account. Note that taxes and transfers can be an arbitrary (non-linear) function of the state $s_{t}$.

\section{Quantitative Analysis}

In this section, we provide a quantitative analysis based on a special version of the model. To this end, Section IV.a first presents the model specification for the special case of interest. Sections IV.b and IV.c then discuss the equilibrium conditions for the special case and our computational approach. Section IV.d briefly discusses the data and Section IV.e presents the calibration of the partial equilibrium model. Section IV.f and IV.g discuss the life-cycle implications of the model with respect to portfolio choice, insurance, and welfare. The next three sections analyze the model response to changes in contract enforcement, labor market risk, and risk aversion based on the partial equilibrium version of the model. ${ }^{7}$ Section IV.k concludes with a discussion how to calibrate the general equilibrium version of the model.

\section{a) Specification}

We set the period length to one year. We assume that the economy is in stationary equilibrium and drop the time index $t$. We further assume that the exogenous individual state

\footnotetext{
${ }^{7}$ We do not re-calibrate the model when we change the value of one parameter and in this sense we conduct a comparative statics analysis. Our results barely change if we re-calibrate the model to match all targets before and after the parameter change.
} 
has two components, $s=\left(s_{1}, s_{2}\right)$. The first component, $s_{1}$, denotes the age of a household, which can take on 9 values, $s_{1}=1, \ldots, 9$, corresponding to the following 9 age groups: 25 and younger, 26 - 30, $31-36, \ldots, 56-60$, and older than 60 . We assume that households stochastically age with the transitions from one age group to another age group governed by transition probabilities $\pi\left(s_{1}^{\prime} \mid s_{1}\right)$. We assume that households cannot move up more than one age group at a time, and choose $\pi\left(s_{1}+1 \mid s_{1}\right)$ so that so that households spend on average 5 years in the first 8 age groups. That is, for $s_{1} \leq 8$ we have $\pi\left(s_{1} \mid s_{1}\right)=4 / 5$ and $\pi\left(s_{1}+1 \mid s_{1}\right)=1 / 5$. Households in the oldest age group die stochastically and the probability of death is chosen so that these households live on average a further 25 years. Old households who leaves the model are replaced by households in the youngest age group.

The second component of the state, $s_{2}$, describes human capital risk. Both $s_{1}$ and $s_{2}$ affect human capital accumulation through the $\epsilon$-function appearing in the human capital equation (1) as $\epsilon\left(s_{1}, s_{2}\right)=\varphi\left(s_{1}\right)-\delta_{h}+\eta\left(s_{2}\right)$. We interpret $\varphi$ as a learning-by-doing parameter which depends on age and which, in our calibration below, is stronger for younger households so that $\varphi\left(s_{1}\right)>\varphi\left(s_{1}+1\right)$. The parameter $\delta_{h}$ is the average depreciation rate of human capital in the economy. We have set the labor productivity parameter $z=1$ so that all labor income risk is generated through the human capital shock $\eta$, which is assumed to be i.i.d. over time and across households and independent of household age $s_{1} \cdot{ }^{8}$ Assuming that the cost of human capital in terms of consumption goods $\phi$ is constant, the return to human capital is given by $r_{h}\left(s_{1}, s_{2}\right)=\phi \tilde{r}_{h}+\varphi\left(s_{1}\right)-\delta_{h}+\eta\left(s_{2}\right)$. Normalizing the mean of the human capital shocks to zero, or $\sum_{s_{2}} \eta\left(s_{2}\right) \pi\left(s_{2}\right)=0$, we find that the expected human capital returns for a household of age $s_{1}$ are $\bar{r}_{h}\left(s_{1}\right)=\sum_{s_{2}} r_{h}\left(s_{1}, s_{2}\right) \pi\left(s_{2}\right)=\phi \tilde{r}_{h}+\varphi\left(s_{1}\right)-\delta_{h}$. For the oldest household group, $s_{1}=9$, we assume that human capital returns are low enough so that they only invest in financial capital yielding a portfolio return equal to the risk-free $r_{f}$ (retirement).

\footnotetext{
${ }^{8}$ In Krebs, Kuhn, and Wright (2015) we consider the more general version with additional shocks to $z$.
} 
With this specification in hand, we can verify that human capital accumulation decisions satisfy various non-negativity constraints on human capital investment. For example, in equilibrium the restriction holds that total human capital investment inclusive of learningby-doing is always non-negative: $\varphi\left(s_{1}\right) h_{t}+\phi x_{h t} \geq 0$.

\section{b) Equilibrium Conditions}

Given the assumption made so far, the intensive-form Bellman equation (21) for households of age $s_{1} \leq 8$ becomes

$$
\begin{gathered}
\tilde{V}\left(s_{1}\right)=\max _{\tilde{c}, \theta^{\prime}}\left\{\frac{\tilde{c}^{1-\gamma}}{1-\gamma}+\beta(1-\tilde{c})^{1-\gamma} \sum_{s_{1}^{\prime}, s_{2}^{\prime}}\left(1+r\left(\theta^{\prime}, s_{1}^{\prime}, s_{2}^{\prime}\right)\right)^{1-\gamma} \tilde{V}\left(s_{1}^{\prime}\right) \pi\left(s_{2}^{\prime}\right) \pi\left(s_{1}^{\prime} \mid s_{1}\right)\right\} \\
\text { s.t. } 1=\theta_{h}^{\prime}+\sum_{s_{1}^{\prime}, s_{2}^{\prime}} \frac{\theta_{a}^{\prime}\left(s_{1}^{\prime}, s_{2}^{\prime}\right) \pi\left(s_{2}^{\prime}\right) \pi\left(s_{1}^{\prime} \mid s_{1}\right)}{1+r_{f}}, 0 \leq \tilde{c} \leq 1, \theta_{h}^{\prime} \geq 0 \\
\left(\frac{\tilde{V}\left(s_{1}^{\prime}\right)}{\tilde{V}_{d}\left(s_{1}^{\prime}\right)}\right)^{\frac{1}{1-\gamma}}\left(1+r\left(\theta^{\prime}, s_{1}^{\prime}, s_{2}^{\prime}\right)\right) \geq\left(1+r_{h}\left(s_{1}^{\prime}, s_{2}^{\prime}\right)\right) \theta_{h}^{\prime} \quad \forall\left(s_{1}^{\prime}, s_{2}^{\prime}\right)
\end{gathered}
$$

with

$$
\begin{aligned}
\tilde{V}_{d}\left(s_{1}\right)= & \max _{\tilde{c}_{d}}\left\{\frac{\tilde{c}_{d}^{1-\gamma}}{1-\gamma}+p \beta\left(1-\tilde{c}_{d}\right)^{1-\gamma} \sum_{s_{1}^{\prime}, s_{2}^{\prime}}\left(1+r_{h d}\left(s_{1}^{\prime}, s_{2}^{\prime}\right)\right)^{1-\gamma} \tilde{V}_{d}\left(s_{1}^{\prime}\right) \pi\left(s_{2}^{\prime}\right) \pi\left(s_{1}^{\prime} \mid s_{1}\right)\right. \\
& \left.(1-p) \beta\left(1-\tilde{c}_{d}\right)^{1-\gamma} \sum_{s_{1}^{\prime}, s_{1}^{\prime}}\left(1+r_{h d}\left(s_{1}^{\prime}, s_{2}^{\prime}\right)\right)^{1-\gamma} \pi\left(s_{2}^{\prime}\right) \tilde{V}\left(s_{1}\right) \pi\left(s_{1}^{\prime} \mid s_{1}\right)\right\}
\end{aligned}
$$

for $\gamma \neq 1$. In the case of log-utility, the intensive-form Bellman equation (21) becomes

$$
\begin{aligned}
\tilde{V}\left(s_{1}\right)= & \max _{\theta^{\prime}}\left\{\ln (1-\beta)+\frac{\beta}{1-\beta} \ln \beta+\frac{\beta}{1-\beta} \sum_{s_{1}^{\prime}, s_{2}^{\prime}} \ln \left(1+r\left(\theta^{\prime}, s_{1}^{\prime}, s_{2}^{\prime}\right) \pi\left(s_{2}^{\prime}\right) \pi\left(s_{1}^{\prime} \mid s_{1}\right)\right.\right. \\
& \left.+\beta \sum_{s_{1}^{\prime}} \tilde{V}\left(s_{1}^{\prime}\right) \pi\left(s_{1}^{\prime} \mid s_{1}\right)\right\}
\end{aligned}
$$




$$
\begin{array}{ll}
\text { s.t. } & 1=\theta_{h}^{\prime}+\sum_{s_{1}^{\prime}, s_{2}^{\prime}} \frac{\theta_{a}^{\prime}\left(s_{1}^{\prime}, s_{2}^{\prime}\right) \pi\left(s_{2}^{\prime}\right) \pi\left(s_{1}^{\prime} \mid s_{1}\right)}{1+r_{f}}, \theta_{h}^{\prime} \geq 0 \\
& e^{(1-\beta)\left(\tilde{V}\left(s_{1}^{\prime}\right)-\tilde{V}_{d}\left(s_{1}^{\prime}\right)\right)}\left(1+r\left(\theta^{\prime}, s_{1}^{\prime}, s_{2}^{\prime}\right) \geq\left(1+r_{h d}\left(s_{1}^{\prime}, s_{2}^{\prime}\right)\right) \theta_{h}^{\prime} \quad \forall\left(s_{1}^{\prime}, s_{2}^{\prime}\right)\right.
\end{array}
$$

with

$$
\begin{aligned}
\tilde{V}_{d}\left(s_{1}\right)= & \ln (1-\beta)+\frac{\beta}{1-\beta} \log \beta+\frac{\beta}{1-\beta} \sum_{s_{1}^{\prime}, s_{2}^{\prime}} \log \left(1+r_{h d}\left(s_{1}^{\prime}, s_{2}^{\prime}\right) \pi\left(s_{2}^{\prime}\right) \pi\left(s_{1}^{\prime} \mid s_{1}\right)\right. \\
& +p \beta \sum_{s_{1}^{\prime}} \tilde{V}_{d}\left(s_{1}^{\prime}\right) \pi\left(s_{1}^{\prime} \mid s_{1}\right)+(1-p) \beta \sum_{s_{1}^{\prime}} \tilde{V}\left(s_{1}^{\prime}\right) \pi\left(s_{1}^{\prime} \mid s_{1}\right)
\end{aligned}
$$

From (24) it immediately follows that the optimal portfolio choice, $\theta$, and the optimal consumption-saving choice, $\tilde{c}$, only depend on age $s_{1}$ but not on human capital shocks $s_{2}$. In other words, household consumption and portfolio choices are independent are independent of i.i.d. shocks. This in turn implies that the relevant aggregate state, $\Omega$, only depends on age, $s_{1}$. The stationary $\Omega$ is then determined by the following set of equations, defined first for $s_{1}=1$ :

$$
\Omega(1)=N\left[\frac{4}{5} \sum_{s_{2}^{\prime}}(1-\tilde{c}(1))\left(1+r\left(\theta^{\prime}(1), 1, s_{2}^{\prime}\right)\right) \pi\left(s_{2}^{\prime}\right) \Omega(1)+\lambda\right]
$$

and then $\forall s_{1}$ with $2 \leq s_{1} \leq 8$ :

$$
\begin{aligned}
\Omega\left(s_{1}\right)= & N\left[\frac{4}{5} \sum_{s_{2}^{\prime}}\left(1-\tilde{c}\left(s_{1}\right)\right)\left(1+r\left(\theta^{\prime}\left(s_{1}\right), s_{1}, s_{2}^{\prime}\right)\right) \pi\left(s_{2}^{\prime}\right) \Omega\left(s_{1}\right)+\right. \\
& \left.\frac{1}{5} \sum_{s_{2}^{\prime}}\left(1-\tilde{c}\left(s_{1}-1\right)\right)\left(1+r\left(\theta^{\prime}\left(s_{1}-1\right), s_{2}^{\prime}\right)\right) \pi\left(s_{2}^{\prime}\right) \Omega\left(s_{1}-1\right)\right]
\end{aligned}
$$

and then lastly:

$$
\Omega(9)=N\left[\frac{24}{25}(1-\tilde{c}(9))\left(1+r_{f}\right) \Omega(9)+\frac{1}{5}(1-\tilde{c}(8))\left(1-\theta_{h}(8)\right)\left(1+r_{f}\right) \Omega(8)\right]
$$

where $N$ is a normalization constant chosen to ensure $\sum_{s_{1}} \Omega\left(s_{1}\right)=1$. Note that $(25)$ is the stationary version of (23) for the current model set-up, where we have already used the assumption that new-born households begin life in age group (state) $s_{1}=1$. 
Suppose we choose $\lambda_{a}=1$. Taking into account that $\rho\left(s_{1}\right)=1$ for $s_{1}=1, \ldots, 8$ and $\theta_{h}(9)=0$, we find that the market clearing condition (22) becomes

$$
\tilde{K}=\frac{\sum_{s_{1}}\left(1-\tilde{c}\left(s_{1}\right)\right)\left(1-\theta_{h}\left(s_{1}\right)\right) \Omega\left(s_{1}\right)}{\left(1+\lambda_{h}\right) \phi \sum_{s_{1} \neq 9}\left(1-\tilde{c}\left(s_{1}\right)\right) \theta_{h}\left(s_{1}\right) \Omega\left(s_{1}\right)}
$$

where $\lambda$ in (25) and $\lambda_{h}$ in (26) are related through

$$
\lambda=[1+\bar{r}(\theta(1))]\left[\frac{1}{25}(1-\tilde{c}(9)) \Omega(9)+\lambda_{h} \phi \sum_{s_{1} \neq 9}\left(1-\tilde{c}\left(s_{1}\right)\right) \theta_{h}\left(s_{1}\right) \Omega\left(s_{1}\right)\right]
$$

where $\bar{r}(\theta(1))$ is the average investment return for a household of age group $s_{1}=1$. Equations (24), (25), and (26) determine a stationary recursive equilibrium for this specification of the model.

\section{c) Computation}

For the general equilibrium analysis, one needs to solve the three equations (24), (25), and (26). The algorithm for doing so works as follows. First, pick an aggregate capital-to-labor ratio, $\tilde{K}$, which determines the rental rates $\tilde{r}_{k}$ and $\tilde{r}_{h}$ and therefore also the investment return function $r$. Second, given the values for the investment returns, solve the intensiveform household decision problem (24) and recover the stationary state $\Omega$. Third, use the values for $\theta, \tilde{c}$, and $\Omega$, to determine a new value for $\tilde{K}$ using (26). Finally, iterate until convergence. Note that in the log-utility case with $\rho\left(s_{1}\right)=1$ there is no need to solve for $\tilde{c}$ since we have $\tilde{c}=1-\beta$.

We solve the partial equilibrium problem (24) by iteration. More precisely, consider the case $\gamma \neq 1$ and define the values $\tilde{V}^{k}\left(s_{1}\right)$ and $\tilde{V}_{d}^{k}\left(s_{1}\right)$, recursively by

$$
\begin{aligned}
\tilde{V}^{k+1}\left(s_{1}\right)= & \left\{\frac{\left(\tilde{c}^{k}\left(s_{1}\right)\right)^{1-\gamma}}{1-\gamma}+\right. \\
& \left.\beta\left(1-\tilde{c}^{k}\left(s_{1}\right)\right)^{1-\gamma} \sum_{s_{1}^{\prime}, s_{2}^{\prime}}\left(\theta_{h}^{k}\left(s_{1}\right)\left(1+r_{h}\left(s_{1}^{\prime}, s_{2}^{\prime}\right)\right)+\theta_{a}^{k}\left(s_{1}, s_{1}^{\prime}, s_{2}^{\prime}\right)\right)^{1-\gamma} \tilde{v}^{k}\left(s_{1}\right) \pi\left(s_{2}^{\prime}\right) \pi\left(s_{1}^{\prime} \mid s_{1}\right)\right\}
\end{aligned}
$$




$$
\tilde{c}^{k}\left(s_{1}\right)=1-\left(\beta \sum_{s_{1}^{\prime}, s_{2}^{\prime}}\left(\theta_{h}^{k}\left(s_{1}\right)\left(1+r_{h}\left(s_{1}^{\prime}, s_{2}^{\prime}\right)\right)+\theta_{a}^{k}\left(s_{1}, s_{1}^{\prime}, s_{2}^{\prime}\right)\right)^{1-\gamma} \pi\left(s_{2}^{\prime}\right) \pi\left(s_{1}^{\prime} \mid s_{1}\right)\right)^{\frac{1}{\gamma}}
$$

and

$$
\begin{aligned}
\tilde{V}_{d}^{k+1}\left(s_{1}\right)= & \frac{\left(\tilde{c}_{d}\left(s_{1}\right)\right)^{1-\gamma}}{1-\gamma}+\beta\left(1-\tilde{c}_{d}\left(s_{1}\right)\right)^{1-\gamma} p \sum_{s_{1}^{\prime}, s_{2}^{\prime}}\left(1+r_{h d}\left(s_{1}^{\prime}, s_{2}^{\prime}\right)\right)^{1-\gamma} \tilde{v}_{d}^{k}\left(s_{1}^{\prime}\right) \pi\left(s_{2}^{\prime}\right) \pi\left(s_{1}^{\prime} \mid s_{1}\right) \\
& +\beta\left(1-\tilde{c}_{d}\left(s_{1}\right)\right)^{1-\gamma}(1-p) \sum_{s_{1}^{\prime}, s_{2}^{\prime}}\left(1+r_{h d}\left(s_{1}^{\prime}, s_{2}^{\prime}\right)\right)^{1-\gamma} \pi\left(s_{2}^{\prime}\right) \tilde{V}^{k}\left(s_{1}^{\prime}\right) \pi\left(s_{1}^{\prime} \mid s_{1}\right) \\
\tilde{c}_{d}\left(s_{1}\right)= & 1-\left(\beta \sum_{s_{1}^{\prime}, s_{2}^{\prime}}\left(1+r_{h d}\left(s_{1}^{\prime}, s_{2}^{\prime}\right)\right)^{1-\gamma} \pi\left(s_{2}^{\prime}\right) \pi\left(s_{1}^{\prime} \mid s_{1}^{\prime}\right)\right)^{\frac{1}{\gamma}}
\end{aligned}
$$

where the portfolio choices $\left(\theta_{h}^{k}\left(s_{1}\right), \theta_{a}^{k}\left(s_{1}\right)\right)$ for each $s_{1}$ are the solution to

$$
\begin{array}{ll} 
& \max _{\theta_{h}, \theta_{a}} \sum_{s_{1}^{\prime}, s_{2}^{\prime}}\left(\theta_{h}\left(1+r_{h}\left(s_{1}^{\prime}, s_{2}^{\prime}\right)\right)+\theta_{a}\left(s_{1}^{\prime}, s_{2}^{\prime}\right)\right)^{1-\gamma} \pi\left(s^{\prime}\right) \\
\text { s.t. } & \theta_{h}+\sum_{s_{1}^{\prime}, s_{2}^{\prime}} \frac{\theta_{a}\left(s_{1}^{\prime}, s_{2}^{\prime}\right) \pi\left(s_{2}^{\prime}\right) \pi\left(s_{1}^{\prime} \mid s_{1}\right)}{1+r_{f}}=1 \\
& \theta_{h}\left(1+r_{h}\left(s_{1}^{\prime}, s_{2}^{\prime}\right)\right)+\theta_{a}\left(s_{1}^{\prime}, s_{2}^{\prime}\right) \geq \theta_{h}\left(1+r_{h d}\left(s_{1}^{\prime}, s_{2}^{\prime}\right)\right)\left(\frac{\tilde{V}_{d}^{k}\left(s_{1}^{\prime}\right)}{\tilde{V}^{k}\left(s_{1}^{\prime}\right)}\right)^{\frac{1}{1-\gamma}}
\end{array}
$$

The intensive-from value function and the corresponding optimal portfolio choice are obtained by taking the $\operatorname{limit} \tilde{V}=\lim _{k \rightarrow \infty} \tilde{V}^{k}, \tilde{V}_{d}=\lim _{k \rightarrow \infty} \tilde{V}^{k}$, and $\theta=\lim _{k \rightarrow \infty} \theta^{k}$. To solve the portfolio problem (29) for given $k$ and $s_{1}$, we first fix $\theta_{h}^{k}\left(s_{1}\right)=\bar{\theta}_{h}^{k}\left(s_{1}\right)$ and find $\theta_{a}^{k}\left(s_{1}\right)$ solving (29) for given $\bar{\theta}_{h}^{k}\left(s_{1}\right)$. To this end, for each $s_{1}^{\prime}$, order the pairs $\left(s_{1}^{\prime}, s_{2}^{\prime}\right)$ so that $r_{h}\left(s_{1}, 1\right)>r_{h}\left(s_{1}, 2\right)>\ldots>r_{h}\left(s_{1}, S\right)$. Given $s_{1}$ suppose that the participation constraint is binding for the first $J\left(s_{1}\right)$ states. Then for the first $J\left(s_{1}\right)$ states $\theta_{a}^{k}\left(s_{1}\right)$ is given by $\theta_{a}^{k}\left(s_{1}, s_{1}^{\prime}, s_{2}^{\prime}\right)=\bar{\theta}_{h}^{k}\left(s_{1}\right)\left[\left(1+r_{h d}\left(s_{1}^{\prime}, s_{2}^{\prime}\right)\right)\left(\frac{\tilde{V}_{d}^{k}\left(s_{1}^{\prime}\right)}{\tilde{V}^{k}\left(s_{1}^{\prime}\right)}\right)^{\frac{1}{1-\gamma}}-\left(1+r_{h}\left(s_{1}^{\prime}, s_{2}^{\prime}\right)\right)\right] \quad$ for $\quad\left(s_{1}^{\prime}, s_{2}^{\prime}\right)=1, \ldots, J\left(s_{1}\right)$

while for the remaining states, we have

$$
\theta_{a}^{k}\left(s_{1}, s_{1}^{\prime}, s_{2}^{\prime}\right)=\bar{r}^{k}\left(s_{1}\right)-\bar{\theta}_{h}^{k}\left(s_{1}\right)\left(1+r_{h}\left(s_{1}^{\prime}, s_{2}^{\prime}\right)\right)
$$


where $\bar{r}^{k}\left(s_{1}\right)$ is determined by the portfolio constraint in (29). Using the corresponding first-order conditions it is easy to see that, for given $\bar{\theta}_{h}^{k}\left(s_{1}\right)$, the solution $\theta_{a}^{k}\left(s_{1}\right)$ to (29) is determined by $(30)$, where $J\left(s_{1}\right)$ is the smallest number for which the portfolio choice satisfies the participation constraint. Finally, we find optimal $\theta_{h}^{k}\left(s_{1}\right)$ using a standard one-dimensional optimization routine.

\section{d) Data}

For the calibration and the results discussed below, we use data on earnings and financial wealth drawn from the Survey of Consumer Finances (SCF). The SCF is a triennial survey of U.S. households and we use data from 1989 to 2013. For most steps, we follow Krebs, Kuhn, and Wright (2015) with our construction and treatment of the data. Our measure of earnings (labor income) is wages and salaries plus two-thirds of the farm and business income (if applicable). Our measure of financial wealth is net worth, defined as the sum of the consolidated household balance sheet (including net housing wealth). All data has been deflated using the BLS consumer price index for urban consumers (CPI-U-RS)

We follow Heathcote et al. (2010) for the sample selection and confine attention to households with household head age 23 years and older. Specifically, we drop the wealthiest $1.47 \%$ of households in each calender year, which makes the sample more comparable to that of the Panel Study of Income Dynamics (PSID) and the Consumer Expenditure Survey (CEX). Further, we drop all households that report negative labor income or that report positive hours worked but have missing labor income or that report positive labor income but zero or negative hours worked. We also drop in each year households with a wage rate that is below half the minimum wage of the respective year, where we compute the wage rate by dividing labor income by total hours worked.

We construct separately for each survey year life-cycle profiles of median log earnings and 
financial wealth to earnings ratios. We smooth life-cycle profiles separately for each survey year using linear least squares on a cubic polynomial in age and average the smoothed profiles across survey years to remove time effects. ${ }^{9}$ We compute earnings growth rates from age differences in earnings of the smoothed, cross-sectional earnings profiles.

\section{e) Calibration: Partial Equilibrium}

In this section, we calibrate the partial equilibrium version of the economy, that is, we find values for the expected investment returns $r_{f}$ and $\bar{r}_{h}\left(s_{1}\right)=\phi \tilde{r}_{h}+\varphi\left(s_{1}\right)-\delta_{h}$ without specifying the production function that generates these returns. We calibrate an annual risk-free rate of $r_{f}=3 \%$, in line with Kaplan and Violante (2010) and roughly in line with Huggett et al. (2011) and Krueger and Perri (2006) who use a 4\% annual risk-free rate, but also deduct capital income taxes.

We choose the age-dependent expected human capital returns, $\bar{r}_{h}\left(s_{1}\right)$, to match life-cycle profile of earnings growth of the median household in the data for the first 8 age groups. Specifically, we first construct a life-cycle profile of annual median household earnings and earnings growth as described in the previous section, and then construct a corresponding life-cycle profile of earnings growth for the relevant age groups. The result is depicted in Figure 1 and shows the expected life-cycle pattern. Earnings growth rate are very high for young households, monotonically decreasing in age, and turn negative for households older than 50 .

We assume that human capital shocks, $\eta$, are approximately normally distributed, that is, we choose the probabilities $\pi\left(s_{2}\right)$ and the realizations $\eta\left(s_{2}\right)$ to approximate a normal distribution with mean 0 and standard deviation $\sigma_{\eta}=0.15$. The parameter $\sigma_{\eta}$ measures human capital risk and our choice of $\sigma_{\eta}=0.15$ is motivated by the following considerations.

\footnotetext{
${ }^{9}$ We only use observations until age 60 for the regression.
} 
In the model economy, labor income of an individual household in period $t$ is given by $y_{h t}=\tilde{r}_{h} h_{t}$, so that the growth rate of labor income is equal to the growth rate of human capital: $y_{h, t+1} / y_{h t}=h_{h, t+1} / h_{t}$. We can use the equilibrium solution to compute the human capital growth between year $t$ and year $t+1$. Neglecting transitions across age groups $s_{1}$, this yields:

$$
\frac{h_{t+1}}{h_{t}}=\beta\left(\theta_{h}\left(s_{1, t-1}\right)\left(1+\phi \tilde{r}_{h}+\varphi\left(s_{1, t}\right)-\delta_{h}+\eta\left(s_{2 t}\right)\right)+\theta_{a}\left(s_{1, t-1}, s_{1 t}, s_{2 t}\right)\right)
$$

Equation (31) can be written as

$$
\ln y_{h, t+1}=\ln y_{h t}+d\left(s_{1}\right)+\tilde{\eta}_{t},
$$

where $d\left(s_{1}\right)$ is a constant and $\left\{\tilde{\eta}_{t}\right\}$ is a sequence of i.i.d. random variables with

$$
\sigma_{\tilde{\eta}}^{2}\left(s_{1}\right)=\theta_{h}^{2}\left(s_{1}\right) \sigma_{\eta}^{2}+\operatorname{var}\left[\theta_{a} \mid s_{1}\right]
$$

Hence, the logarithm of labor income follows a random walk with drift $d$ and innovation term $\tilde{\eta}_{t} .{ }^{10}$ The random walk specification is often used by the empirical literature to model the permanent component of labor income risk (Carroll and Samwick (1997), Meghir and Pistaferri (2004), and Storesletten et al. (2004)). Thus, their estimate of the standard deviation of the error term for the random walk component of annual labor income can be used to find a value for $\sigma_{\tilde{\eta}}^{2}$ for given portfolio choices $\theta_{h}$ and $\theta_{a}$. For young households, we will see below that $\theta_{h}$ is close to one and insurance payments, $\theta_{a}\left(s_{2}\right)$, are small, so that we have $\sigma_{\tilde{\eta}}^{2} \approx \sigma_{\eta}^{2}$. In our baseline calibration, we use $\sigma_{\eta}=.15$, which lies on the lower end of the spectrum of estimates found by the empirical literature. For example, Carroll and Samwick (1997) find .15, Meghir and Pistaferri (2004) estimate .19, and Storesletten et al. (2004) have .25 (averaged over age-groups and, if applicable, over business cycle conditions). All

\footnotetext{
${ }^{10}$ We have $\tilde{\eta}_{t}$ instead of $\tilde{\eta}_{t+1}$ in equation (32), and the latter is the common specification for a random walk. However, this is not a problem if the econometrician observes the idiosyncratic depreciation shocks with a one-period lag. In this case, (32) is the correct equation from the household's point of view, but a modified version of (31) with $\tilde{\eta}_{t+1}$ replacing $\tilde{\eta}_{t}$ is the specification estimated by the econometrician.
} 
these studies use labor income before transfer payments, which is the relevant variable from our point of view.

For the baseline calibration, we assume that households who default regain access to financial markets after 7 years: $(1-p)=1 / 7$. Finally, we assume a degree of relative risk aversion of $\gamma=1$ (log-utility) and set the annual discount factor to $\beta=0.95 .{ }^{11}$ We choose the human capital rental rate, $\phi \tilde{r}_{h}$, to match the average value of the financial wealth to earnings ratio for households age 23-60 (see Figure 2 below).

\section{f) Portfolio Choice and Human Capital Returns}

In this subsection, we examine household's portfolio allocation between financial assets and human capital. To this end, we first use current earnings as a proxy for human capital and construct the life-cycle profile of the ratio of financial wealth to earnings in the model and in the data. ${ }^{12}$ Figure 2 depicts the result and shows that the model does an excellent job of matching this life-cycle profile, though it somewhat over-predicts the financial wealth holdings of the oldest households. Note that the model matches the life-cycle average of the financial wealth to earnings ratio by construction since we choose the human capital rental rate, $\phi \tilde{r}_{h}$, accordingly. However, we have no additional parameter to match the shape of the life-cycle profile depicted in Figure 2.

The advantage of using the financial wealth to earnings ratio as a measure of portfolio choice, as we have done in Figure 2, is the ease with which this variable can constructed from the data without imposing additional assumptions. The disadvantage is that current earnings is a very crude proxy of human capital. We therefore construct an alternative measure of portfolio choice that uses the present value of future lifetime earnings as a proxy

\footnotetext{
${ }^{11}$ An alternative calibration approach is to require the model to match a given expected human capital return for the young and then use $\beta$ to match the observed earnings growth rate of the young.

${ }^{12}$ In the model, this ratio is computed as $\frac{1-\theta_{h}\left(s_{1}\right)}{\phi \tilde{r}_{h} \theta_{h}\left(s_{1}\right)}$.
} 
for human capital, where future earnings are discounted at the risk-free rate implied by the calibrated model. Figure 3 depicts the result and shows that the model lines up reasonably well with the data. However, the model over-predicts the human capital share, and this over-prediction becomes more severe with age. The explanation for this is that in the model older households are almost fully insured against the human capital loss upon retirement, which means that the model tends to overstate the value of human capital. Clearly, this type of "model error" becomes more important with age. ${ }^{13}$

In order to help understand the portfolio allocation decisions of households, Figure 4 presents the excess return to investing in human capital as a function of age. As shown in the figure, young households face an excess return of almost ten percent, explaining why the young hold very little financial wealth. Moreover, excess human capital returns in the vicinity of 10 percent are in line with estimated rates of return to on-the-job-training (Blundell et al. 1999 and Mincer 1994). The excess return available to the oldest working households is less than one-half of one percent, which explains why they hold so much more financial wealth than the young.

\section{g) Consumption Insurance and Welfare}

The youngest households not only hold little financial wealth, but they are also dramatically under-insured. Figure 5 plots a measure of consumption insurance, the insurance coefficient, defined as one minus the ratio of the standard deviation of household consumption growth to the standard deviation of household income growth. As shown in the figure, households of the youngest age group are insured against only one third of their income risk, whereas

\footnotetext{
${ }^{13}$ Note that the value of human capital in the model is always equal to the expected present discounted value of lifetime earnings if future earnings are discounted using the relevant intertemporal marginal rate of substitution and the model earnings process is used to computed expected lifetime earnings. The difference between the model implication and the data depicted in Figure 3 arises because i) different discount rates are used and ii) the model earnings process (in conjunction with the almost full-insurance result for older households) does not capture the data well after age 60 .
} 
older households are insured against roughly 90 percent of their income risk.

Figure 6 examines the welfare consequences of this underinsurance, depicting the equivalent variation of moving to full insurance measured in units of lifetime consumption. As shown in the figure, the youngest households would require an increase of almost 7.5 percent in their annual consumption to be as well off as if they had access to full insurance. Thus, for young households the welfare loss due to lack of insurance against labor market risk are quite substantial. Further, even for households age 40 these welfare losses amount to 3 percent of lifetime consumption. For the older working households, however, this equivalent variations has fallen to less than one-half of one percent.

\section{h) The Effect of Changing Personal Bankruptcy Regimes}

Figures 7 through 10 explore the consequences of changing the details of the personal bankruptcy regime either by increasing the time for which a household is considered bankrupt, or by allowing for wage garnishment during bankruptcy. Figures 7 and 8 focus on the effects of changing the duration of bankruptcy from an average of 7 years to an average of 10 years. As shown in Figure 7, the human capital portfolio share of the youngest households rises from almost one, denoting no financial wealth, to a value greater than one, denoting negative net financial assets. This increase is reflected throughout the age distribution, although the increases are quite modest in size and decline with age. Figure 8 shows that, although human capital investment increases, insurance against human capital risk is almost unchanged, with the blue and red lines almost atop one another. The reason is that households prefer, on the margin, to borrow more in order to invest in human capital and not buy any further insurance. This is also confirmed by the green line in Figure 8 which shows the effect on risk sharing if the household is constrained from increasing their human capital portfolio. In this case, risk sharing is increased across all age groups, with the largest effect on the young, who are most likely to be constrained, and whose consumption insurance rises from about a 
third of income risk to roughly 40 percent of income risk.

Figures 9 and 10 repeat the above analysis, this time by introducing garnishment of 20 percent of wages while bankrupt. Figure 9 shows that this results in a qualitatively similar increase in human capital portfolio shares with the portfolio share of the very youngest working households exceeding one by roughly 7 percent. Borrowing levels are also positive (the human capital share remains larger then one) for households throughout their 30's and into their 40's. Figure 10 also shows that there is no significant increase in risk sharing. If households are constrained from investing more in human capital (the green line), consumption insurance increases dramatically with the young now insured against almost 60 percent of their income risk.

\section{i) The Effect of Changing Human Capital Risk}

We now consider an increase in the standard deviation of labor income shocks from $\sigma_{\eta}=0.15$ to $\sigma_{\eta}=0.20$. Figure 11 shows that the effect of this increase on human capital investment is not monotone: young households increase, while older households decrease, their investments in human capital. This is the result of two offsetting forces. On the one hand, an increase in labor income risk makes investments in human capital less attractive for a given mean return. On the other hand, increases in labor income risk make the prospect of declaring bankruptcy less attractive as the household must bear the full cost of this risk while bankrupt. For young households, who desire to hold more human capital, the latter effect dominates, while for older households the former effect dominates.

Figure 12 shows the implications of these choices for consumption insurance. Whereas the blue line shows that consumption insurance is increased for all household ages, the green line depicts what would have happened to consumption insurance if the households had been unable to adjust their human capital holdings. As shown in the figure, the youngest 
households would have increased their consumption insurance even further, while the oldest households would have had less consumption insurance as the costs of declaring bankruptcy were significantly reduced and thus the extent of available insurance constraints was reduced.

\section{j) The Effect of Changing Risk Aversion}

Lastly, Figures 13 and 14 illustrate the effects of changing the coefficient of relative risk aversion from $\gamma=1$ to $\gamma=2$ keeping all factor returns constant at the levels calibrated in the baseline. Figure 13 shows that greater risk aversion, everything else equal, results in greater investments in human capital. This result stems from the fact that declaring bankruptcy is now more expensive, and hence households are able to borrow more for the purpose of investing in human capital. This offsets the fact that more risk averse individuals are otherwise less inclined to invest in risky assets.

Figure 14 shows that consumption insurance is also improved for households with higher risk aversion reflecting both a greater demand for insurance and greater possibilities for insurance resulting from the fact that default is less desirable for such households. Also shown in the figure, as depicted by the green line, if that consumption insurance would have increased still further if households had been unable to increase their investments in risky human capital.

\section{k) Closing the Model (General Equilibrium)}

We now return to the full general equilibrium model (endogenous investment returns) and show how to complete the model calibration by introducing a production function and imposing a number of aggregate targets. We use a Cobb-Douglas production function $f(\tilde{K})=A \tilde{K}^{\alpha}$, where $0<\alpha<1$ is capital's share in output and $A$ is a productivity parameter. In this case, the rental rates of physical capital and human capital are given by

$$
\tilde{r}_{k}=\alpha A \tilde{K}^{\alpha-1}
$$




$$
\tilde{r}_{h}=(1-\alpha) A \tilde{K}^{\alpha}
$$

As in Krebs, Kuhn, and Wright (2015), we target an aggregate share of capital income, $\tilde{r}_{k} K / Y$, of 0.32 so that $\alpha=0.32$. We also follow Krebs, Kuhn, and Wright (2015) and target an aggregate capital-to-output ratio of 2.94. This target in conjunction with the target $r_{f}=\tilde{r}_{k}-\delta_{k}=0.03$ yields $\tilde{r}_{k}=0.1085$ and $\delta_{k}=0.0785$

Recall that in the partial equilibrium calibration we have chosen the value of $\phi \tilde{r}_{h}$ to match the average financial-wealth-to-earnings ratio from the SCF for households age 23-60. Given that the values for capital's share in output/income and $\tilde{r}_{k}$ and $\delta_{k}$ are also pinned down, the only way to have the general equilibrium model match a particular target for the aggregate capital-to-output ratio is to vary $\lambda$ in (25), respectively $\lambda_{h}$ in (26), which is the approach taken Krebs, Kuhn, and Wright (2015).

The calibration approach discussed so far determines $\phi \tilde{r}_{h}$, the rental rate of human capital in consumption units, but does not determine separately $\phi$ and $\tilde{r}_{h}$. To resolve this indeterminacy, Krebs, Kuhn, and Wright (2015) impose the (somewhat arbitrary) condition that $\tilde{K}=0.4$, where the value 0.4 for the capital-to-labor ratio is in line with the results obtained in Krebs (2003) using a model with $\phi=1$ (one unit of the consumption/capital good can be transformed into one unit of human capital).

Finally, we note that the life-cycle profile of human capital returns, $\bar{r}_{h}\left(s_{1}\right)$, which is pinned down by the partial equilibrium calibration, and the human capital rental rate, $\phi \tilde{r}_{h}$ (see above), imply a life-cycle profile for the difference $\varphi\left(s_{1}\right)-\delta_{h}$. However, the values for the learning-by-doing parameters and the human capital depreciation rate are still not separately identified. Krebs, Kuhn, and Wright (2015) choose $\delta_{h}=0.04$, which then pins down the life-cycle profile of learning-by-doing parameters. 


\section{Appendix}

\section{Proof of Proposition 1}

To simplify the notation, suppress the dependence on the aggregate state, $\Omega$, and consider a household of cohort $n=0$. Further, define an action variable $x_{t}=\left(c_{t}, \theta_{t+1}\right)$ and a feasibility correspondence, $\Gamma$, that for every $\left(w_{t}, s_{t}\right)$ restricts the choice of $\left(w_{t+1}, x_{t}\right)$ according to (15). Using this notation, the household maximization problem reads

$$
\begin{array}{ll}
\max & E\left[\sum_{t=0}^{\infty} \beta^{t} \nu_{t} u\left(x_{t} \mid w_{0}\right]\right. \\
\text { s.t. } & \left(w_{t+1}, x_{t}\right) \in \Gamma\left(w_{t}, s_{t}\right) \\
& E\left[\sum_{m=0}^{\infty} \beta^{m} \nu_{m} u\left(x_{t+m}\right) \mid w_{0}, s^{t}\right] \geq V_{d}\left(w_{t}, s_{t}\right)
\end{array}
$$

The corresponding Bellman equation reads:

$$
\begin{gathered}
V(w, s)=\max _{x, w^{\prime}}\left\{u(x)+\beta \rho(s) \sum_{s^{\prime}} V\left(w^{\prime}, s^{\prime}\right) \pi\left(s^{\prime} \mid s\right)\right\} \\
\text { s.t. } \quad\left(x, w^{\prime}\right) \in \Gamma(w, s) \\
\quad V\left(w^{\prime}, s^{\prime}\right) \geq V_{d}\left(w^{\prime}, s^{\prime}\right)
\end{gathered}
$$

Define an operator, $T$, that maps semi-continuous functions into semi-continuous functions as

$$
\begin{gathered}
T V(w, s)=\max _{x, w^{\prime}}\left\{u(x)+\beta E\left[V\left(w^{\prime}, s^{\prime}\right) \mid s\right]\right\} \\
\text { s.t. } \quad\left(x, w^{\prime}\right) \in \Gamma(w, s) \\
\\
V\left(w^{\prime}, s^{\prime}\right) \geq V_{d}\left(w^{\prime}, s^{\prime}\right) .
\end{gathered}
$$

A standard contraction mapping argument shows that there is a unique continuous solution, $V_{0}$, to the Bellman equation (A2) without participation constraint if i) $u$ is continuous, ii) $\Gamma$ is compact-valued and continuous, and (19) holds. Extending the argument of Rustichini 
(1998), ${ }^{14}$ it can be shown that $V_{\infty}=\lim _{k \rightarrow \infty} T^{k} V_{0}$ exists, is equal to the maximal solution of the Bellman equation (A2), and is the value function of the sequential maximization problem (A1) if the following four conditions hold: i) $u$ is continuous, ii) $\Gamma$ is compact-valued and continuous, iii) for all states, $(w, s)$, there exists a feasible plan for the sequential problem (A1) so that the corresponding expected lifetime utility (payoff) is greater than $-\infty$, and iv) for any given state, $(w, s)$, the value function of the max-problem without participation constraints satisfies $V_{0}^{*}(w, s)<+\infty$. Thus, to prove proposition 1 it suffices to show that conditions i)-iv) hold.

The continuity of the payoff function, $u$, is obvious. The correspondence, $\Gamma$, is compactvalued since portfolio-choices, $\theta^{\prime}$, are elements of a closed and bounded subset of $\mathbb{R}^{m}$. Closedness follows from the fact that the set is defined by equalities and weak inequalities. Restricting attention to a bounded set can be shown to be without loss of generality. Continuity of the correspondence $\Gamma$ is also straightforward to show. A standard argument shows that conditions iii) and iv) hold if condition (19) is satisfied. This proves proposition 1.

\section{Proof of Proposition 2}

As before, let $V_{0}$ be the solution of the Bellman equation (A2) without the participation constraint. To save space, we only conduct the prove for the case $\gamma \neq 1$. Simple guess-and-verify shows that $V_{0}$ has the following functional form:

$$
V_{0}(w, s)=\tilde{V}_{0}(s) w^{1-\gamma}
$$

where $\tilde{V}_{0}$ is the solution to the intensive-form Bellman equation (22) without participation constraint. Let the operator $T$ be defined as in (A3). We show by induction that if $V_{k}=T^{k} V_{0}$

\footnotetext{
${ }^{14}$ Rustichini (1998) consider a class of dynamic programming problems with participation constraint (incentive compatability constraint) and possibly unbounded utility. However, he requires bi-convergence, which is always satisfied if lifetime-utility is bounded for all feasible paths (Streufert, 1990). Unfortunately, in our problem with $\gamma \geq 1$ the requirement of lower convergence is not satisfied, so that Rustichini (1998) is not directly applicable.
} 
has the functional form, then $V_{k+1}=T^{k+1} V_{0}$ has the functional form. For $k=0$ the claim is true because $V_{0}$ has the functional form. Suppose now $V_{k}$ has the functional form. We then have

$$
\begin{aligned}
V_{k+1}(w, s)= & T V_{k}(w, s) \\
= & \max _{w^{\prime}, c, \theta^{\prime}}\left\{\frac{c^{1-\gamma}}{1-\gamma}+\rho(s) \sum_{s^{\prime}} \tilde{V}_{k}\left(s^{\prime}\right)\left(1+r\left(\theta^{\prime}, s, s^{\prime}\right)\right)^{1-\gamma}\left(w^{\prime}\right)^{1-\gamma} \pi\left(s^{\prime} \mid s\right)\right\} \\
\text { s.t. } \quad & w^{\prime}=\left(1+r\left(\theta^{\prime}, s, s^{\prime}\right)\right)(w-c) \\
& 1=\theta_{h}^{\prime}+\sum_{s^{\prime}} \frac{\theta_{a}^{\prime}\left(s^{\prime}\right) \pi\left(s^{\prime} \mid s\right)}{1+r_{f}} \\
& \sum_{s^{\prime}} \frac{\pi\left(s^{\prime} \mid s\right) \theta_{a}^{\prime}\left(s^{\prime}\right)}{1+r_{f}} \geq-\bar{D} \theta_{h}^{\prime}, \quad \theta_{h}^{\prime} \geq 0 \quad, \quad w^{\prime} \geq 0 \\
& \tilde{V}_{k}\left(s^{\prime}\right)\left(1+r\left(\theta_{h}^{\prime}, \theta_{a}\left(s^{\prime}\right), s, s^{\prime}\right)\right)^{1-\gamma}\left(w^{\prime}\right)^{1-\gamma} \\
& \geq \tilde{V}_{d}\left(s^{\prime}\right)\left(1+r_{h d}\left(s, s^{\prime}\right)\right) \theta_{h}^{\prime} .
\end{aligned}
$$

Clearly, the solution to the maximization problem defined by the right-hand-side of (A5) has the form

$$
\begin{aligned}
w_{k+1}^{\prime} & =\left(1-\tilde{c}_{k+1}(s)\right) w \\
\theta_{k+1}^{\prime} & =\theta_{k+1}^{\prime}(s),
\end{aligned}
$$

where the subscript $k+1$ indicates step $k+1$ in the iteration. Thus, we have $V_{k+1}(w, s)=$ $\tilde{V}_{k+1}(s) w^{1-\gamma}$ where $\tilde{V}_{k+1}$ is defined accordingly.

From proposition 1 we know that $V_{\infty}=\lim _{k \rightarrow \infty} T^{k} V_{0}$ exists and that it is the maximal solution to the Bellman equation (A2) as well as the value function of the corresponding sequential maximization problem (A1). Since the set of functions with this functional form is a closed subset of the set of semi-continuous functions, we know that $V_{\infty}$ has the functional form. This prove proposition 2 . 


\section{Proof of Proposition 3}

From proposition 2 we know that individual households maximize utility subject to the budget constraint and participation constraint if condition (19) is satisfied. Thus, it remains to show that the market clearing condition can be written as (22) and that the law of motion (23) describes the equilibrium evolution of the relative wealth distribution.

For simplicity, we only consider the case of infinitely-live households (one cohort $n=0$ ). For the aggregate value of financial asset holdings we find:

$$
\begin{aligned}
E\left[\frac{\theta_{a, t+1} w_{t+1}}{1+r_{t+1}}\right] & =E\left[\theta_{a, t+1}\left(1-\tilde{c}_{t}\right) w_{t}\right] \\
& =E\left[E\left[\theta_{a, t+1}\left(1-\tilde{c}_{t}\right) w_{t} \mid s_{t}\right]\right] \\
& =E\left[\theta_{a, t+1}\left(1-\tilde{c}_{t}\right) E\left[w_{t} \mid s_{t}\right]\right] \\
& =E\left[w_{t}\right] \frac{E\left[\theta_{a, t+1}\left(1-\tilde{c}_{t}\right) E\left[w_{t} \mid s_{t}\right]\right]}{E\left[w_{t}\right]} \\
& =E\left[w_{t}\right] E\left[\theta_{a, t+1}\left(1-\tilde{c}_{t}\right) \Omega\left(s_{t}\right)\right] .
\end{aligned}
$$

where the first line follows from the budget constraint, the second line from the law of iterated expectations, the third line from the fact that $\theta_{a, t+1}$ and $\tilde{c}_{t}$ are independent of wealth and $s^{t-1}$, and the last line from the definition of $\Omega$. A similar argument shows that

$$
H_{t+1}=E\left[w_{t}\right] \bar{z} E\left[\theta_{h, t+1}\left(1-\tilde{c}_{t}\right) \Omega\left(s_{t}\right)\right]
$$

Dividing the two expressions shows that $\tilde{K}^{\prime}$ is given by (22).

Finally, the law of motion for $\Omega$ can be found as:

$$
\begin{aligned}
\Omega_{t+1}\left(s_{t+1}\right) & =\frac{E\left[w_{t+1} \mid s_{t+1}\right]}{E\left[w_{t+1}\right]} \quad(A 9) \\
& =\frac{E\left[\left(1+r_{t+1}\right)\left(1-\tilde{c}_{t}\right) w_{t} \mid s_{t+1}\right]}{E\left[\left(1+r_{t+1}\right)\left(1-\tilde{c}_{t}\right) w_{t}\right]} \\
& =\frac{E\left[E\left[\left(1+r_{t+1}\right)\left(1-\tilde{c}_{t}\right) w_{t} \mid s_{t}\right] \mid s_{t+1}\right]}{E\left[E\left[\left(1+r_{t+1}\right)\left(1-\tilde{c}_{t}\right) w_{t} \mid s_{t}\right]\right]} \\
& =\frac{E\left[\left(1+r_{t+1}\right)\left(1-\tilde{c}_{t}\right) E\left[w_{t} \mid s_{t}\right] \mid s_{t+1}\right]}{E\left[\left(1+r_{t+1}\right)\left(1-\tilde{c}_{t}\right) E\left[w_{t} \mid s_{t}\right]\right]}
\end{aligned}
$$




$$
\begin{aligned}
& =\frac{E\left[\left(1+r_{t+1}\right)\left(1-\tilde{c}_{t}\right) E\left[w_{t} \mid s_{t}\right] \mid s_{t+1}\right]}{E\left[\left(1+r_{t+1}\right)\left(1-\tilde{c}_{t}\right) E\left[w_{t} \mid s_{t}\right]\right]} \times \frac{E\left[w_{t}\right]}{E\left[w_{t}\right]} \\
& =\frac{E\left[\left(1+r_{t+1}\right)\left(1-\tilde{c}_{t}\right) \Omega_{t}\left(s_{t}\right) \mid s_{t+1}\right]}{E\left[\left(1+r_{t+1}\right)\left(1-\tilde{c}_{t}\right) \Omega_{t}\left(s_{t}\right)\right]},
\end{aligned}
$$

where the second line follows from the budget constraint, the third line from the law of iterated expectations, the fourth line from the fact that $\theta_{t+1}$ and $\tilde{c}_{t}$ are independent of wealth and $s^{t-1}$, and the last line from the definition of $\Omega$. This completes the proof of proposition 3 . 


\section{References}

Alvarez, F., and U. Jermann (2000) "Efficiency, Equilibrium, and Asset Pricing With Risk of Default," Econometrica 68: 775-797.

Andolfatto, D., and M. Gervais (2006) "Human Capital Investment and Debt Constraints," Review of Economic Dynamics 10: 1-30.

Angeletos, G. (2007) "Uninsured Idiosyncratic Investment Risk and Aggregate Saving." Review of Economic Dynamics 10: 1-30.

Ben-Porath, Y. (1967) "The Production of Human capital and the Life-Cycle of Earnings," Journal of Political Economy 75: 352-365.

Blundell, R., Dearden, L., Meghir, C., and B. Sianesi (1999) "Human Capital Investment: The Returns from Education and Training to the Individual, the Firm, and the Economy." Fiscal Studies 20: 1-23.

Carroll, C., and A. Samwick (1997) "The Nature of Precautionary Wealth," Journal of Monetary Economics 40: 41-72.

Cordoba, J., (2008) "US Inequality: Debt Constraints of Incomplete Markets?," Journal of Monetary Economics 55: 350-364.

Guvenen, F., Kuruscu, B., and S. Ozkan (2014) "Taxation of Human Capital and Wage Inequality: A Cross-Country Analysis," Review of Economics Studies 81: 818-850.

Heathcote, J., Perri, F. and G. Violante (2010) "Unequal We Stand: An Empirical Analysis of Economic Inequality in the United States: 1967-2006." Review of Economic Dynamics 13: $15-51$.

Huggett, M., Ventura, G., and A. Yaron (2011) "Source of Lifetime Inequality," American Economic Review 101: 2923-54.

Jones, L., and R. Manuelli (1990) "A Convex Model of Equilibrium Growth: Theory and Policy Implications," Journal of Political Economy 98: 1008-1038.

Kaplan, G., and G. Violante (2010) "How Much Consumption Insurance Beyond SelfInsurance?" American Economic Journal: Macroeconomics 2: 53-87.

Kehoe, T., and D. Levine (1993) "Debt-Constrained Asset Markets," Review of Economic Studies 60: 868-888.

Kocherlakota, N. (1996) "Implications of Efficient Risk Sharing Without Commitment," 
Review of Economic Studies 63: 595-609.

Krebs, T. (2003) "Human Capital Risk and Economic Growth," The Quarterly Journal of Economics 118: 709-744.

Krebs, T., Kuhn, M., and M. Wright (2015) "Human Capital Risk, Contract Enforcement, and the Macroeconomy," American Econmic Review 105: 3223-3272.

Krueger, D., and F. Perri (2006) "Does Income Inequality Lead to Consumption Inequality? Evidence and Theory" Review of Economics Studies, 73: 163-193.

Krueger, D., and H. Uhlig (2006) "Competitive Risk Sharing Contracts with One-Sided Limited Commitment," Journal of Monetary Economics 53: 1661-1691.

Ligon, E., J. Thomas, and T. Worrall (2002) "Informal Insurance: Arrangements with Limited Commitment: Theory and Evidence from Village Economies," Review of Economic Studies 69: 209-244.

Lochner, L., and A. Monge-Naranjo (2011) "The Nature of Credit Constraints and Human Capital," American Economic Review 101: 2487-2529.

Lucas, R. (1988) "On the Mechanics of Economic Development," Journal of Monetary Economics 22: 3-42.

Meghir, C. and L. Pistaferri (2004) "Income Variance Dynamics and Heterogeneity," Econometrica 72: 1-32.

Mincer, J. (1994) "Investment in US Education and Training," NBER Working Paper.

Moll, B. (2014) "Productivity Losses From Financial Frictions: Can Self-Financing Undo Capital Misallocation?", American Economic Review 104: 3186-3221.

Rebelo, S. (1991) "Long-Run Policy Analysis and Long-Run Growth," Journal of Political Economy 99: 500-521.

Rustichini, A. (1998) "Dynamic Programming Solution of Incentive Constrained Problems," Journal of Economic Theory 78: 329-354.

Storesletten, K., Telmer, C., and A. Yaron (2004) "Cyclical Dynamics of Labor Market Risk," Journal of Political Economy

Streufert, P. (1990) "Stationary Recursive Utility and Dynamic Programming under the Assumption of Biconvergence," Review of Economic Studies 57: 79-97. 
Thomas, J., and T. Worrall (1988) "Self-Enforcing Wage Contracts," Review of Economic Studies 55: 541-554.

Trostel, P. (1993) "The Effect of Taxation on Human Capital," Journal of Political Economy 101: 327-350.

Wright, M. (2001) "Investment and Growth with Limited Commitment," Working Paper, Stanford University. 
Figure 1: Earnings growth rates

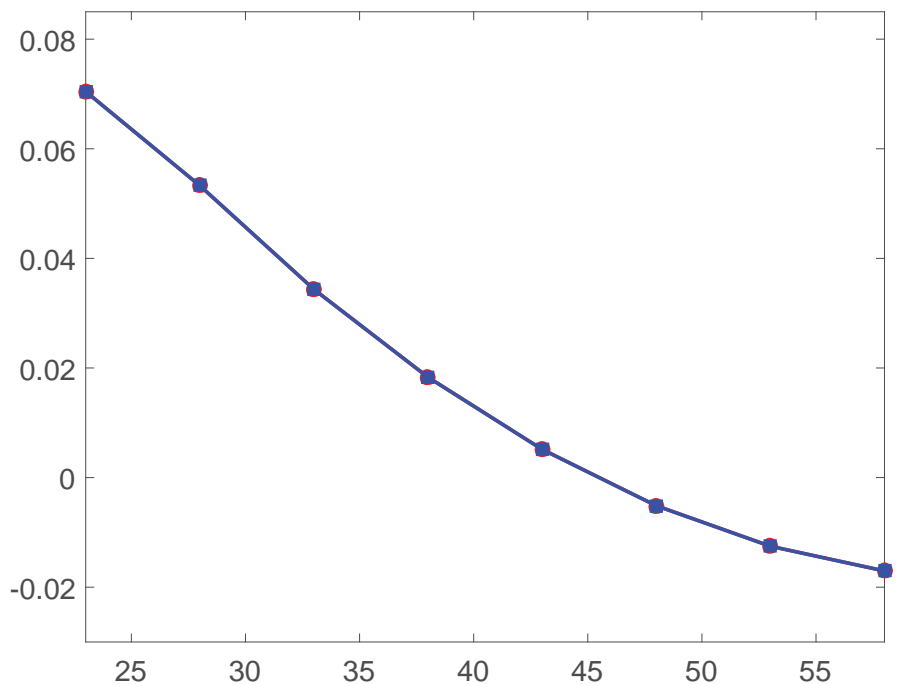

Notes: Earnings growth rates from the model and the data. The red line with circles shows the model, the blue line with squares the data. Horizontal axis shows average age within each age group and vertical axis shows annual earnings growth in percent.

Figure 2: Financial wealth to earnings ratio

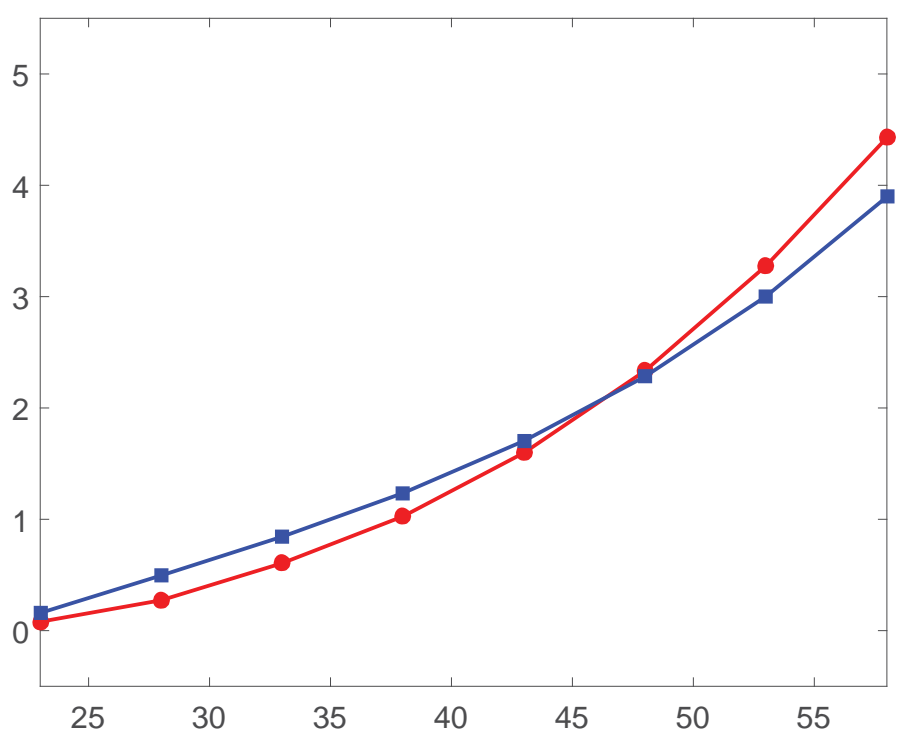

Notes: Wealth-to-income from the model and the data. The red line with circles shows the model, the blue line with squares the data. Horizontal axis shows average age within each age group. 
Figure 3: Human capital portfolio share

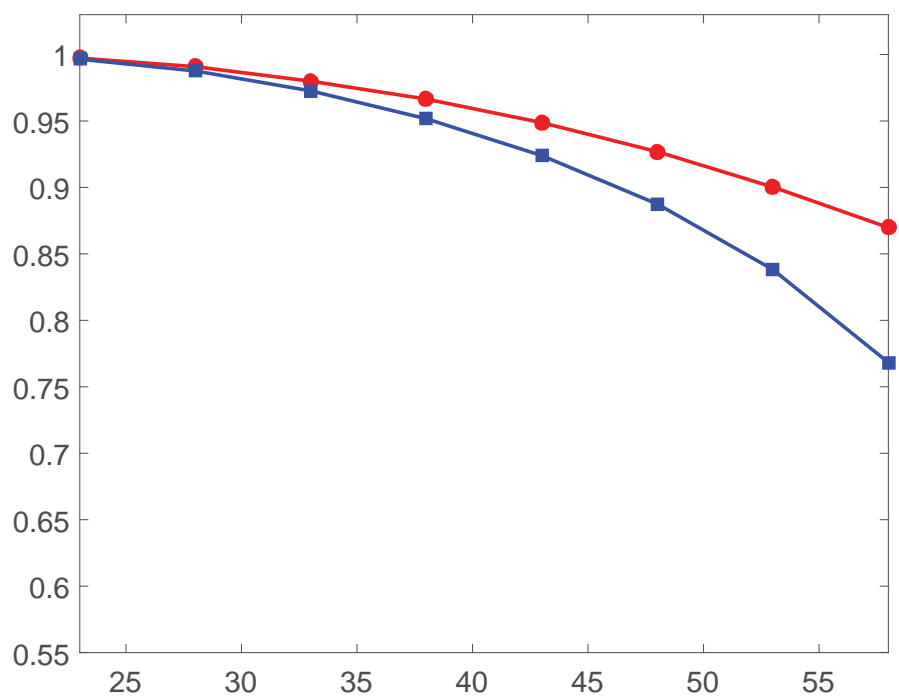

Notes: Human capital portfolio share in total wealth from the model and the data. The red line with circles shows the model, the blue line with squares the data. Horizontal axis shows average age within each age group.

Figure 4: Excess human capital returns

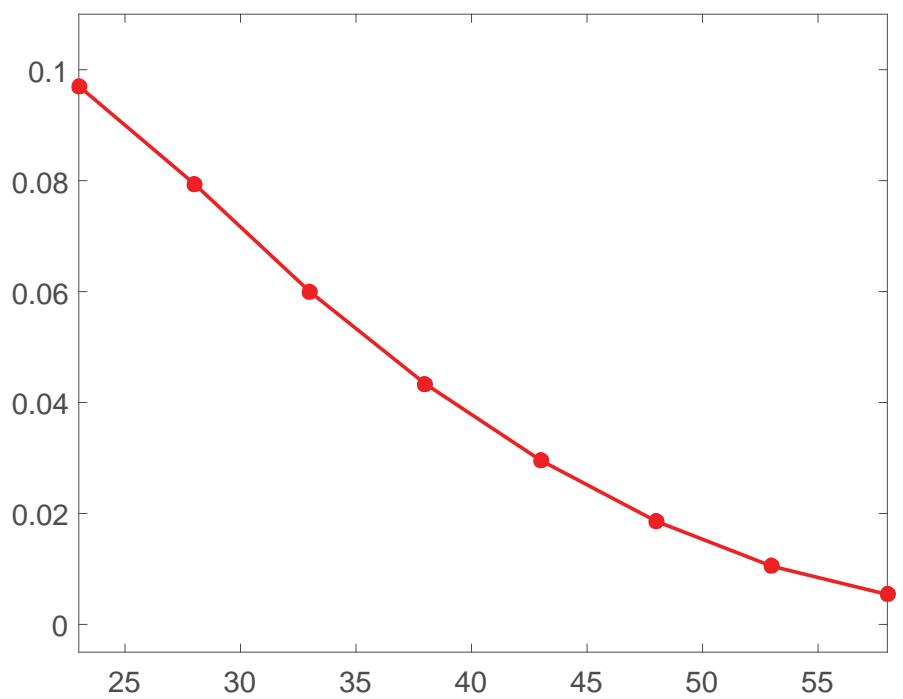

Notes: Excess human capital returns over the life-cycle. Horizontal axis shows average age within each age group. 
Figure 5: Consumption insurance

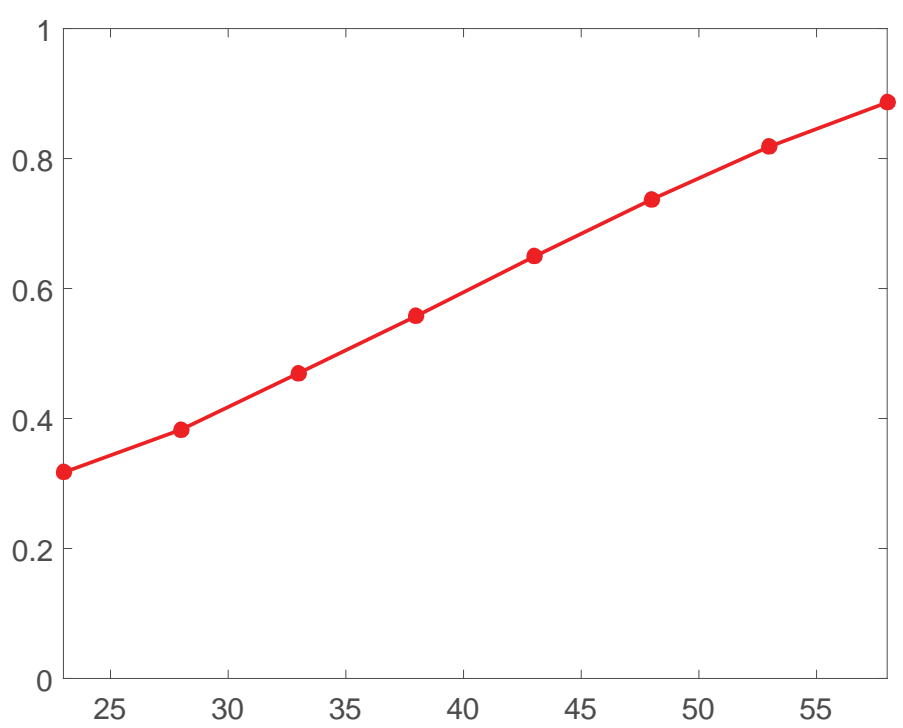

Notes: Consumption insurance of households over the life-cycle. Consumption insurance is measured by the insurance coefficient. The insurance coefficient is constructed as one minus the ratio of the variance of consumption growth over the variance of income growth. Full insurance yields an insurance coefficient of 1 and no insurance (autarky) an insurance coefficient of 0 . Horizontal axis shows average age within each age group.

Figure 6: Welfare cost of underinsurance

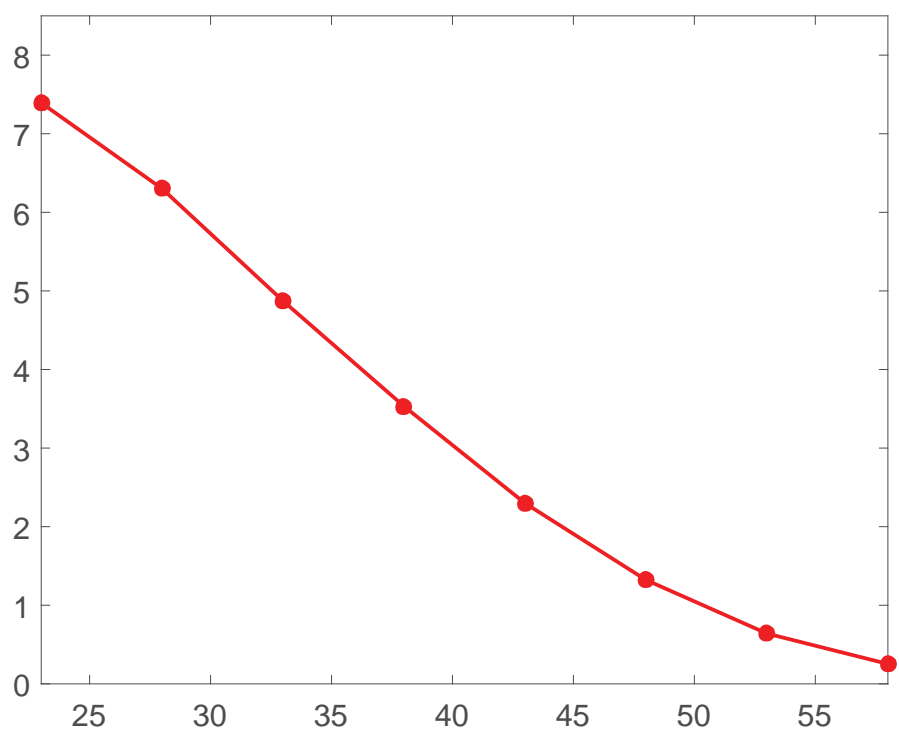

Notes: Welfare costs of limited contract enforcement over the life-cycle. Welfare costs are shown as consumption equivalent variation in percentage points. Horizontal axis shows average age within each age group. 
Figure 7: Human capital portfolio share after change in enforcement

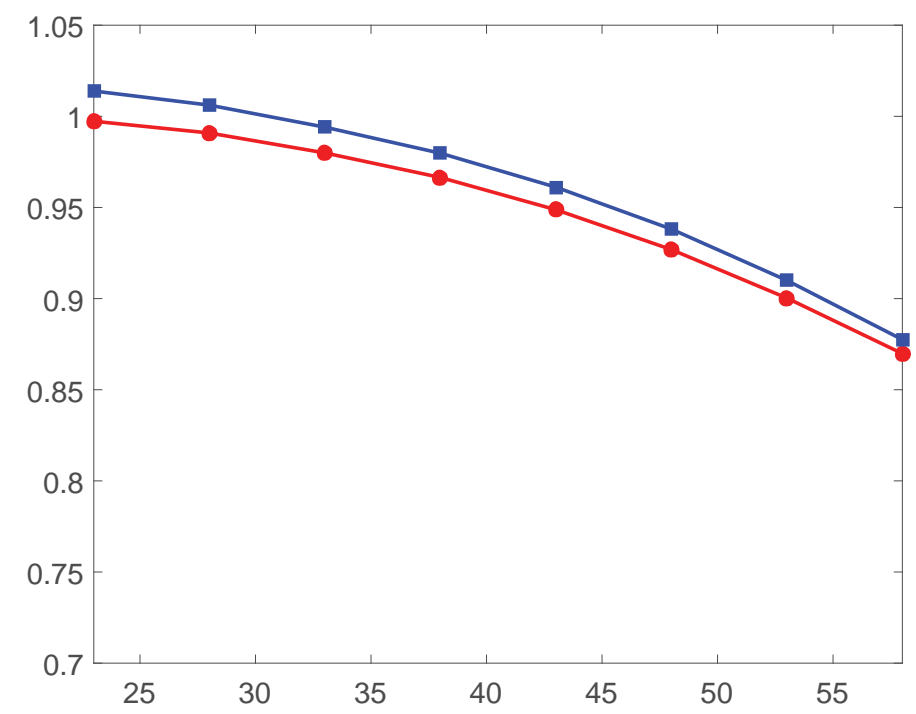

Notes: Human capital portfolio share in total wealth from the baseline model and from comparative statics experiment. The comparative statics experiment changes $p$ from $\frac{1}{7}$ to $\frac{1}{10}$. The red line with circles shows the baseline model, the blue line with squares shows the comparative statics results. Horizontal axis shows average age within each age group.

Figure 8: Consumption insurance after change in enforcement

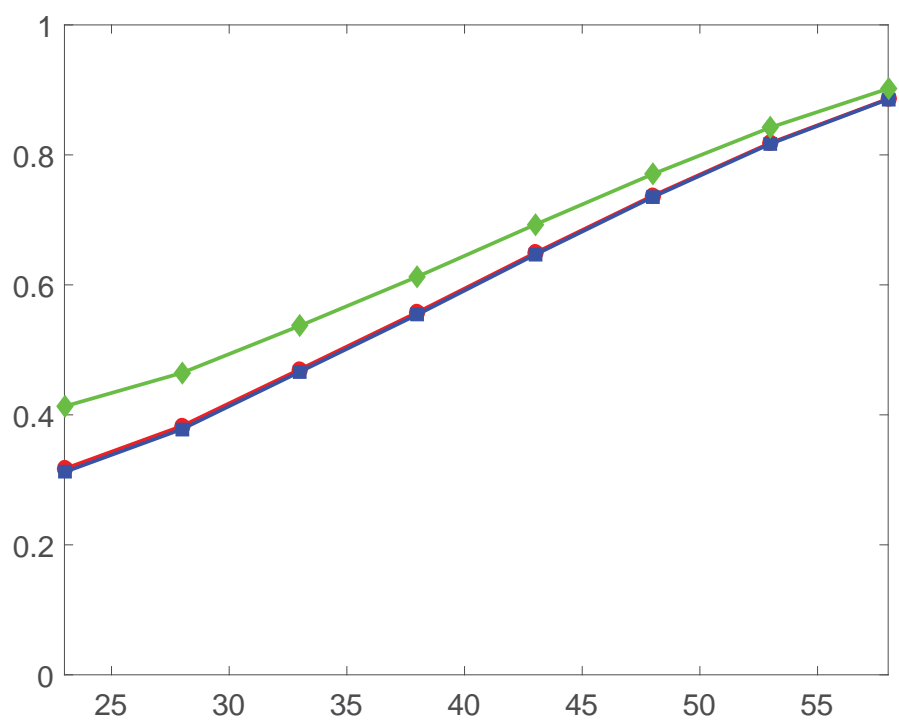

Notes: Consumption insurance of households over the life-cycle for baseline model and from comparative statics experiment. The comparative statics experiment changes $p$ from $\frac{1}{7}$ to $\frac{1}{10}$. The red line with circles shows the baseline model, the blue line with squares shows the comparative statics results, the green line with diamonds shows the comparative statics results with human capital allocation fixed to the baseline. Consumption insurance is measured by the insurance coefficient. Horizontal axis shows average age within each age group. 
Figure 9: Human capital portfolio share after introduction of wage garnishment

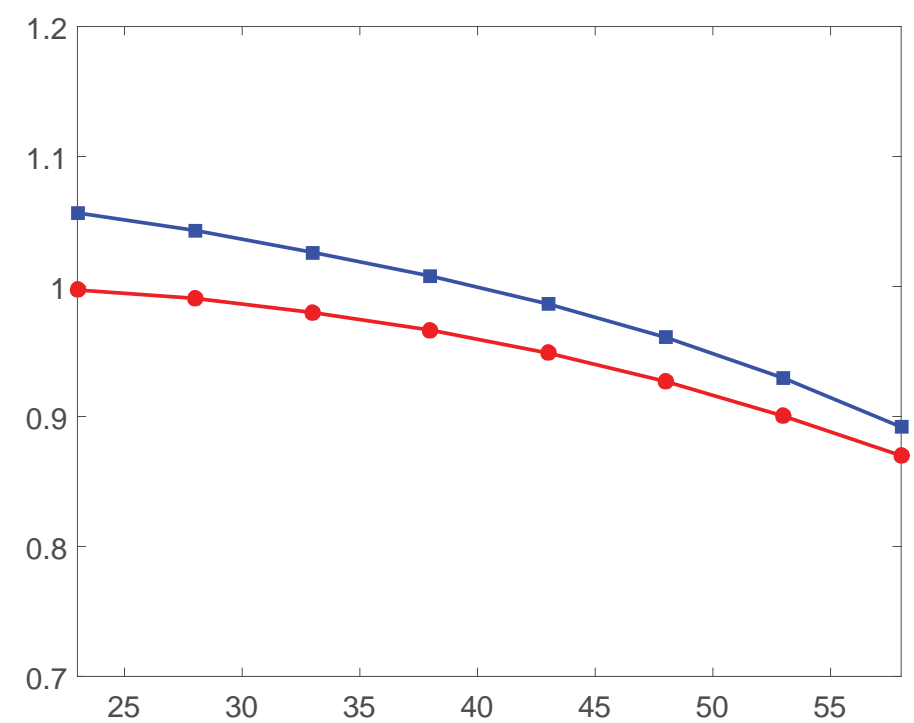

Notes: Human capital portfolio share in total wealth from the baseline model and from comparative statics experiment. The comparative statics experiment introduces a $20 \%$ wage garnishment during default. The red line with circles shows the baseline model, the blue line with squares shows the comparative statics results. Horizontal axis shows average age within each age group.

Figure 10: Consumption insurance after introduction of wage garnishment

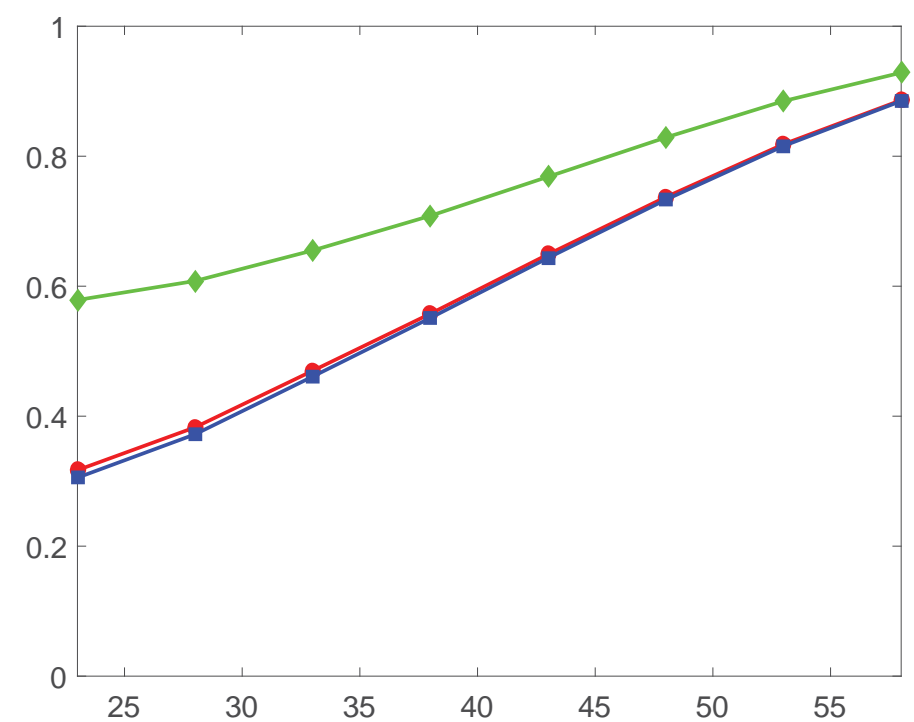

Notes: Consumption insurance of households over the life-cycle for baseline model and from comparative statics experiment. The comparative statics experiment introduces a $20 \%$ wage garnishment during default. The red line with circles shows the baseline model, the blue line with squares shows the comparative statics results, the green line with diamonds shows the comparative statics results with human capital allocation fixed to the baseline. Consumption insurance is measured by the insurance coefficient. Horizontal axis shows average age within each age group. 
Figure 11: Human capital portfolio share after change in human capital risk

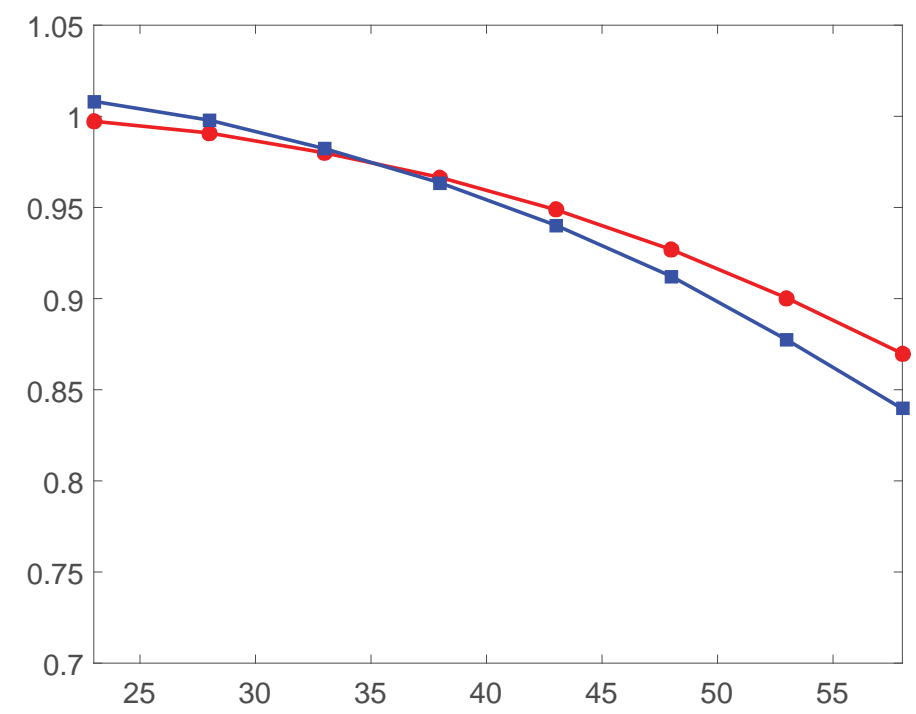

Notes: Human capital portfolio share in total wealth from the baseline model and from comparative statics experiment. The comparative statics experiment changes the standard deviation of human capital risk from 0.15 to 0.2 . The red line with circles shows the baseline model, the blue line with squares shows the comparative statics results. Horizontal axis shows average age within each age group.

Figure 12: Consumption insurance after change in human capital risk

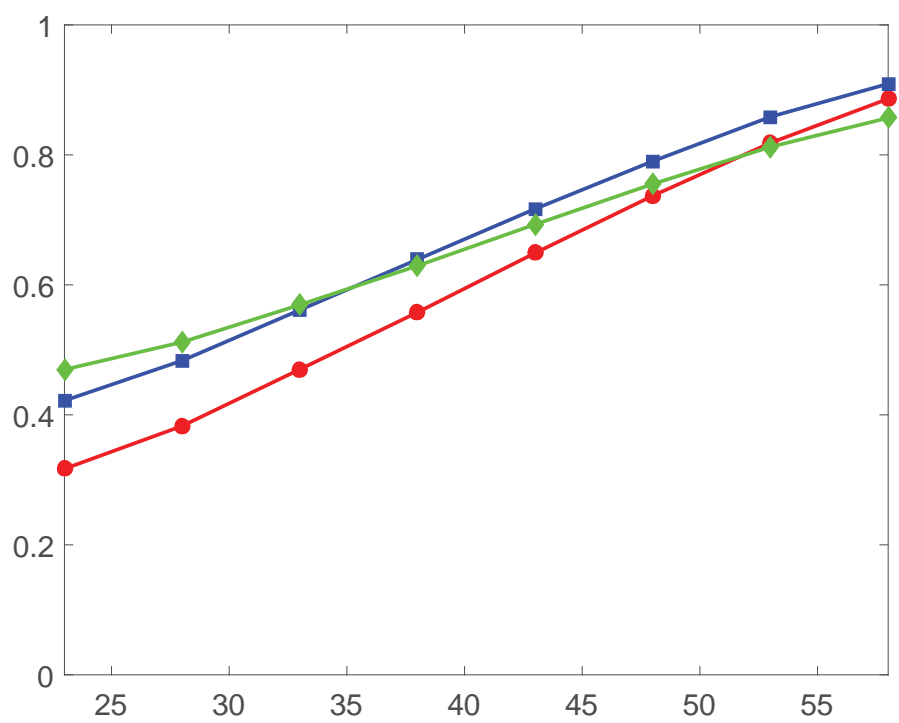

Notes: Consumption insurance of households over the life-cycle for baseline model and from comparative statics experiment. The comparative statics experiment changes the standard deviation of human capital risk from 0.15 to 0.2 . The red line with circles shows the baseline model, the blue line with squares shows the comparative statics results, the green line with diamonds shows the comparative statics results with human capital allocation fixed to the baseline. Consumption insurance is measured by the insurance coefficient. Horizontal axis shows average age within each age group. 
Figure 13: Human capital portfolio share after change in risk aversion

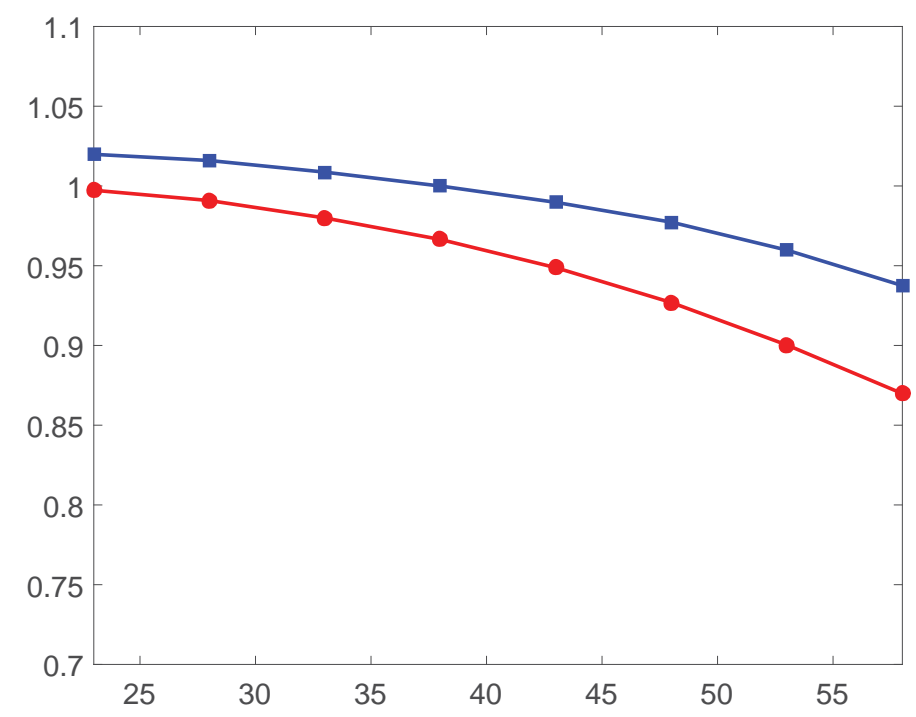

Notes: Human capital portfolio share in total wealth from the baseline model and from comparative statics experiment. The comparative statics experiment changes the degree of relative risk aversion $\gamma$ from 1 to 2 . The red line with circles shows the baseline model, the blue line with squares shows the comparative statics results. Horizontal axis shows average age within each age group.

Figure 14: Consumption insurance after change in risk aversion

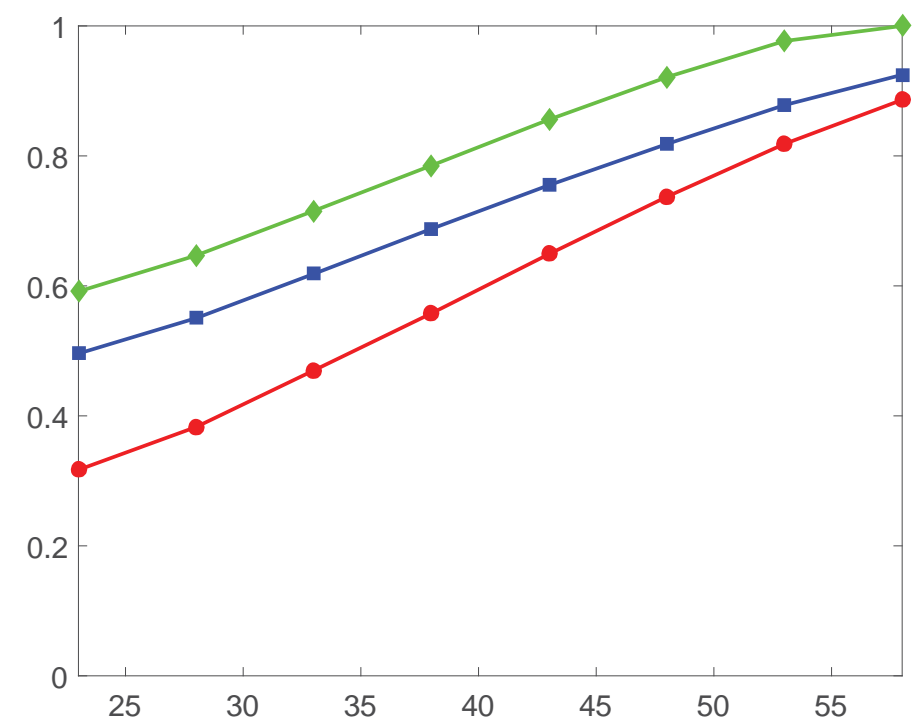

Notes: Consumption insurance of households over the life-cycle for baseline model and from comparative statics experiment. The comparative statics experiment changes the degree of relative risk aversion $\gamma$ from 1 to 2 . The red line with circles shows the baseline model, the blue line with squares shows the comparative statics results, the green line with diamonds shows the comparative statics results with human capital allocation fixed to the baseline. Consumption insurance is measured by the insurance coefficient. Horizontal axis shows average age within each age group. 